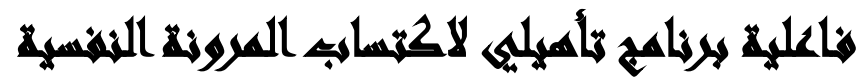

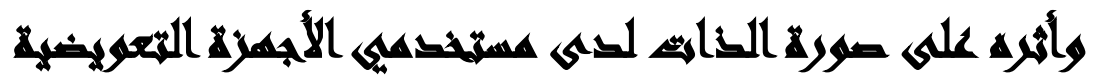

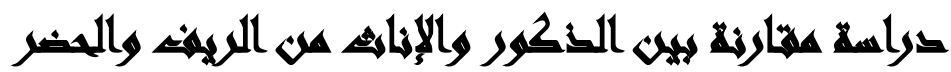

\section{$[\wedge]$}

\author{
كرم عزت(')- محمود السيد أبو النيل(ץ)-زينب بشرى عبد الحميد(r)

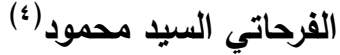

() إدارة الأجهزة الطبية r) كلية الآداب، جامعة العيد عين شمس ؟) كلية الطب، جامعة عين

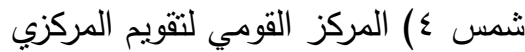

\section{المستخلص}

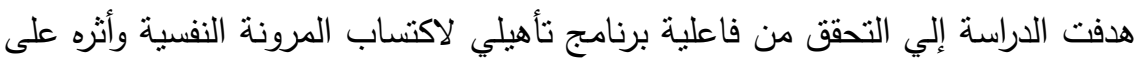

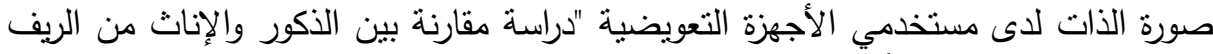

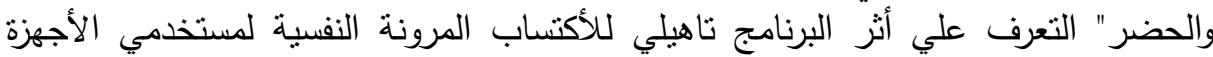

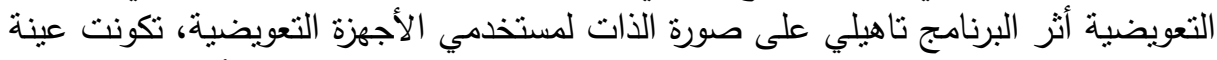

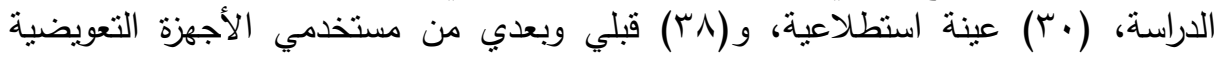

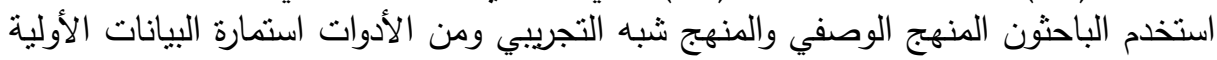

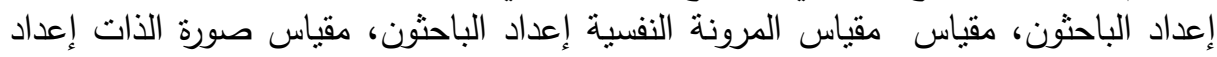

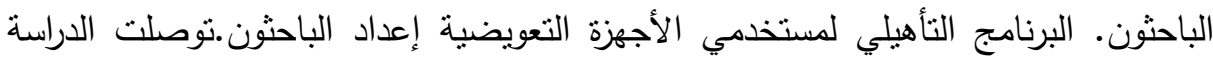
إلي عدد من النتائج أهمها: 1- وجود فروق ذات دلالة إحصائية عند مستوى دلالة (1 +. ·) بين التطبيق القبلى والتطبيق

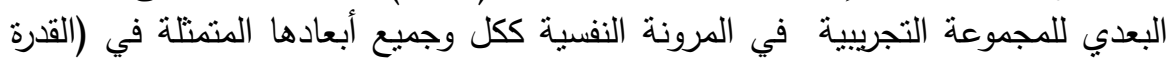

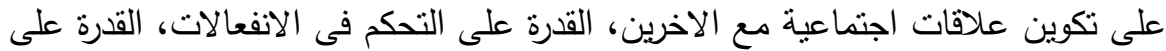

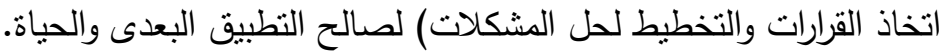

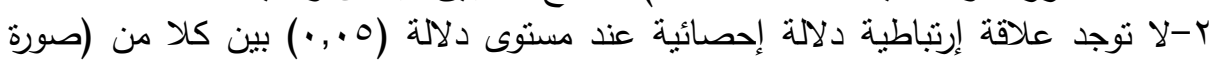

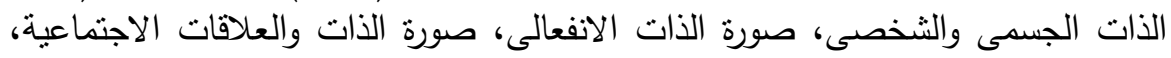

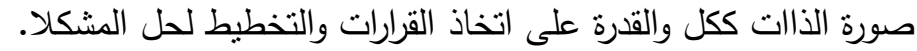

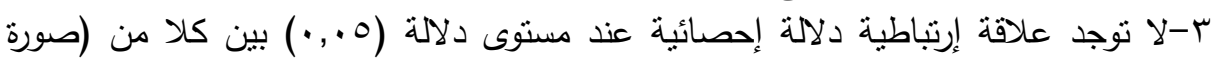

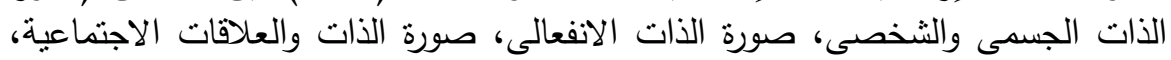
صورة الذات ككل) والمرونة النفسية ككل. 
بذلك توصي الدراسة: 1-الاهتمام بالمعاقين ومعاملتهم المعاملة الحسنة، ودمجهم في المجتمع وإنشراكهم في

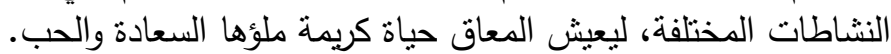

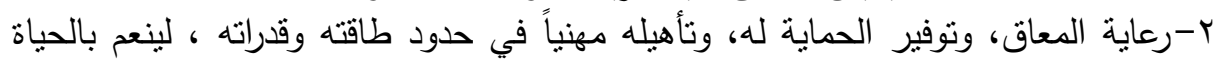

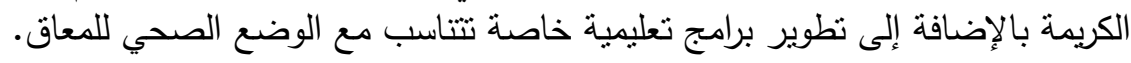

\section{zasianll}

تميز العصر الحالي بجملة من متغيرات سريعة ومتلاحقة أدت إلى العديد من المشكلات والصراعات النفسية التي نواجه الفرد وتؤثر على تواصله مع نفسه ومع الآخرين، فقد كثر

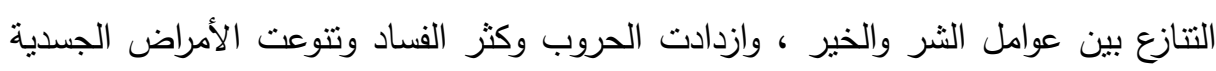

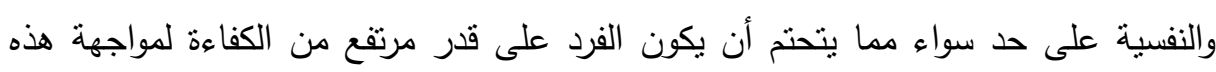
الصراعات، وليحقق أكبر قدر من التوافق والسعادة والصحة النفسية ومن ثم يصبح أكثر تكيفا

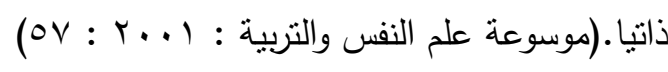
وهناك مسارات متعددة قد تؤدي إلى بتر أعضاء الفرد (مثل مرض اله السكري، أمراض

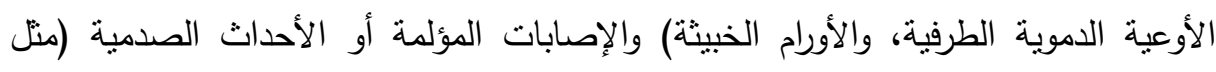

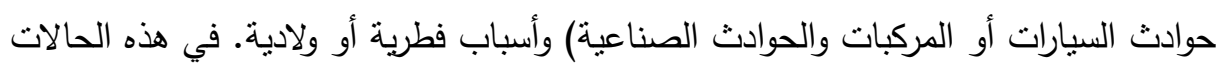

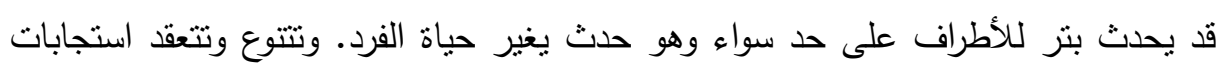
الفرد لفقان الأطراف، وتتأثر بمجموعة من العوامل الثخصية والسريرية والاجتماعية والمادية وهية

ويقوم علماء النفس بدور مهم فى صبياغة وتحديد صعوبات شفاء أو تقام المريض

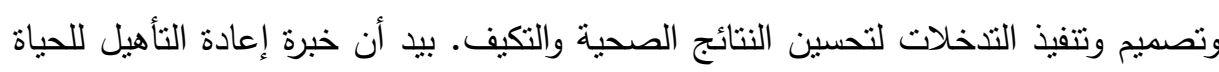

والتعامل مع تحدياتها (Ephraim, Dillingham, , 2003; ونهيم ونعات

تقديم وتاهيل يركز على السمات الإيجابية في الثخصية مثل المرونة النفسية

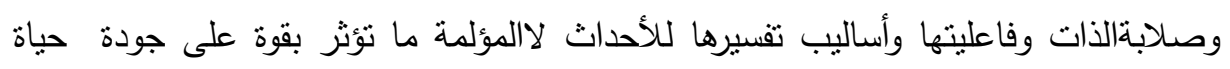

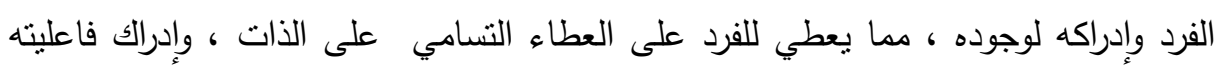

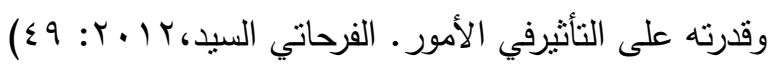


إن تأثثر الإعاقة الذي يتطلب تضافر جهود كبيرة ، ومسئولية مشتركة من كافة

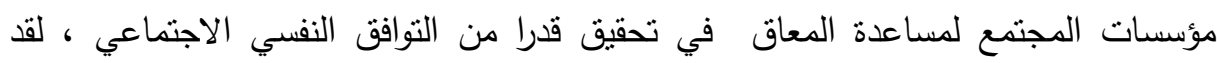
تعددت أساليب العلاج والتأهيل وتضافرت الجهود عبر مؤسسات المختلفة ، من مؤسسات ومراكز متخصصة تعمل في رعاية وتأهيل المعاقين سعياً لتحقيق المرونة النفسية وصورة

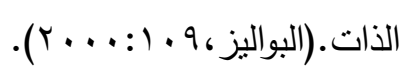

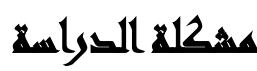

إن مستقبل أى مجتمع يعتمد على قدرة أبناءه في تحقيق الخطوات التي تقوده إلى تحقيق

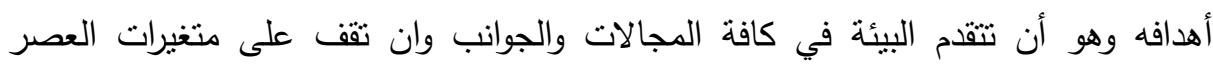

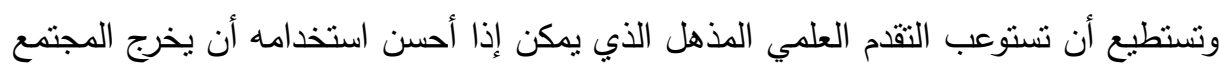

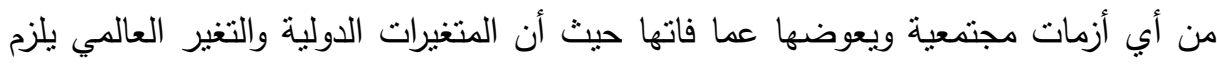

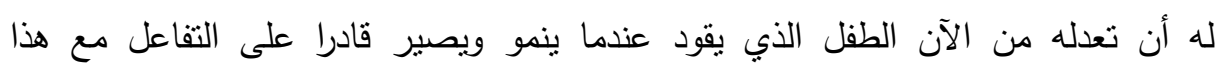

النغيرات. Burger \& Marincek 2007, 1322) وأن كثير من المشكلات سواء طبية، اجتماعية، نفسية، تعليمبة، تأهيلية، ومهنية وهذا

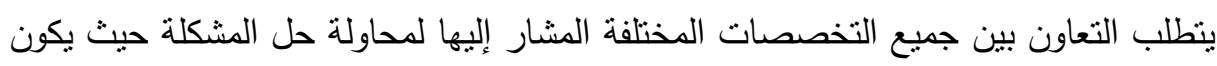
الهدف الأساسي لهذه الفئة هو محاولة تأهيل المعاق والاستفادة من طاقاته المحدودة بحيث

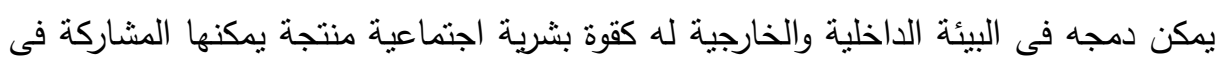
الحياة الاجتماعية بوجه عام.

رغم تعدد الدراسات في مجال الإعاقة الحركية وتعدد متغيراتها ونتائجها وتوصياتها في

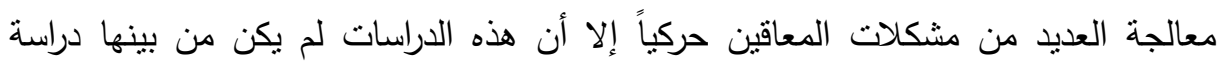
تتاولت برامج التأهيل ودورها في تحقيق المرونة النفسية وصورة الذات في حدود علم الباحث.

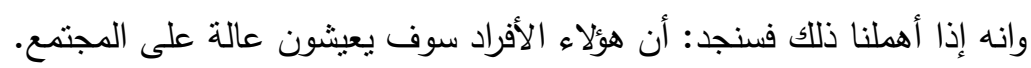

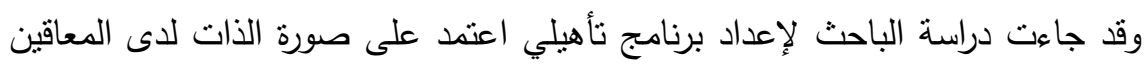
حركياً وهو ما يأمل الباحث أن يكون إضافة فى هذا البرنامج.

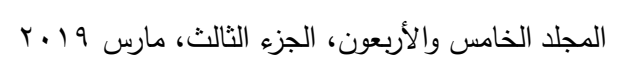


التساؤل الرئيسي: مامدى فاعلية البرنامج التأهيلي في اكتساب المرونة النفسية وأثنر على

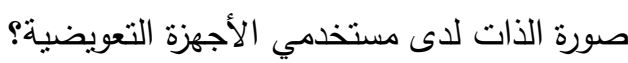

\section{أسئلة الترواسة}

1-ما مدى وجود تأثير للبرنامج التأهيلي على مستخدمي الأجهزة التعويضية في اكتسابهم المرونة النفسية؟ مدئ Y-ما مدى وجود تأثير للبرنامج التأهيلي على صورة الذات لدى مستخدمي الأجهزة التعويضية ؟ مان r-ما مدى وجود علاقة ذات دلالة إحصائية بين صورة الذات والمرونة النفسية لدى مستخدمي الأجهزة التعويضية بعد تطبيق البرنامج التأهيلي؟ دأه دله

\section{أهمية القواسمة}

تهتم الدراسة بالقاء الضوء على فئة هامة جداً وهم مستخدمي الأجهزة التعويضية وتأثير البرنامج التأهيلي المصمم في إكتسابهم المرونة النفسية وتحسين الصورة الذاتية لديهم. الأهمية النظرية: حيث تتمثل في الاطار النظري وعرض موضوعات البحث:

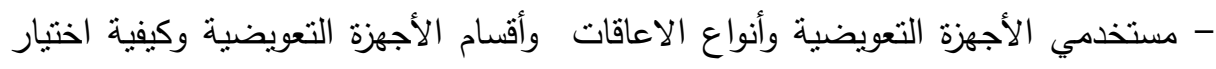

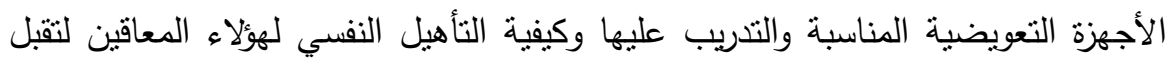
إعاقاتهم. - المرونة النفسية من حيث النشأة والنطور وماهية المرونة والنظريات المفسرة والمرونة النفسية وسمات الأثخاص ذوبي المرونة النفسية - صورة الذات من حيث الجوانب الأساسية المكونة لصورة الذات والعوامل المؤثرة في صورة الذات وتفسير صورة الذات في ضوء الإعاقة الجسمية بتر الأطراف والنظريات المفسرة

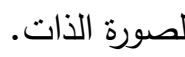




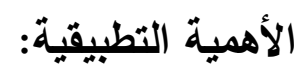

- مساعدة مستخدمي الأجهزة التعويضية في تحسين صورة الذات لديهم من خلال برنامج نأهيلي.

- مساعدة مستخدمي الأجهزة التعويضية في إكتسابهم المرونة النفسية لليهم من خلال

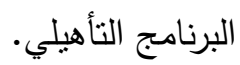

- التوصل إلى مدى قوة العلاقة بين المرونة النفسية والصورة الذاتية لاى مستخدمي الأجهزة

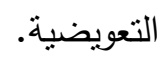

\section{هزوضر التواسما}

ا- نوجد فروق ذات دلالة إحصائية بين التطبيق القبلي والتطبيق البعدي في المرونة النفسية لاى مستخدمى الاجهزة التعويضية لصالح التطبيق البعدي.

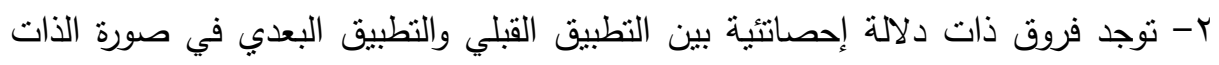
لاى مستخدمى الاجهزة التعويضية لصالح التطبيق البعدي لصالح التطبيق البعدي.

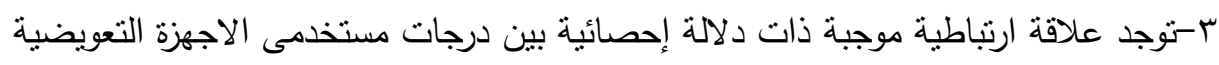
فى التطبيق البعدى لمقياس المرونة النفسية

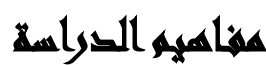

1-البرنامجج التأهيلي: البرنامج عبارة عن جلسات موضوعة على أسس علمية سليمة لفترة زمنية معينة لكل جلسة وذلك لتحقيق أهداف وضع من أجلها البرنامج.

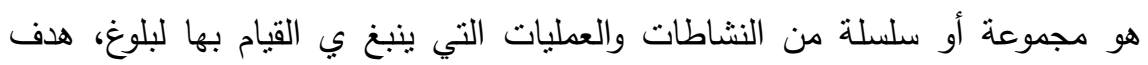

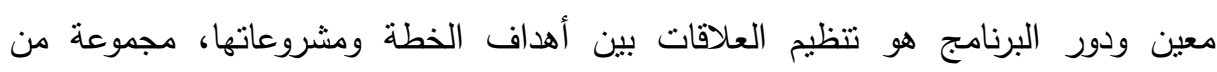
الأنشطة والأساليب المحددة التي تستخدم بهدف تحقيق الأهداف المنوطة بالبرنامج (مدحت

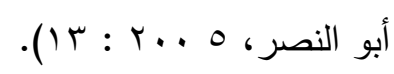


- تعريف البرنامج التأهيلى إجرائياً: هو مجموعة الأنشطة والخبرات والممارسات والخدمات التأهيلية المباثرة وغير المباشرة المخطط لها، والذى يستخدمها الباحث مع مجموعة من مستخدمي الأجهزة التعويضـية بقصد اكسـابهم المرونـة النفسية فى وجـه الضـغوط التىى تسببها إعاقة بتر أطرافهم، وكذلك مساعدتهم فى تحقيق النمو السوى والتوافق النفسى النى وتحقيق الصحة النفسية وفى النهاية إدراكهم الإيجابى لصورة الذات لايهم. r-المرونـة النفسيـة: المرونة النفسية هى القدرة على التكيف في المواقف التي تحمل

الإحباط حيث يلتمس الحلول المختلفة للمشكلات ولايظهر العجز عن مواجهتها.

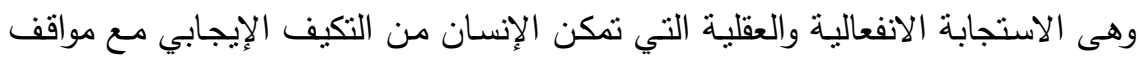

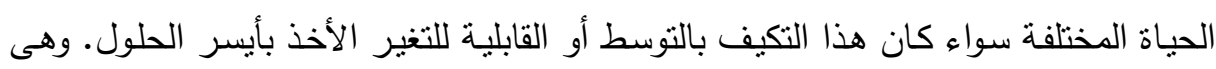
القدرة على التعافي من التأثيرات السلبية لهذه الثدائد أو النكبات أو الأحداث الضاغطة والقدرة

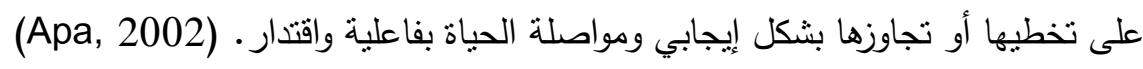

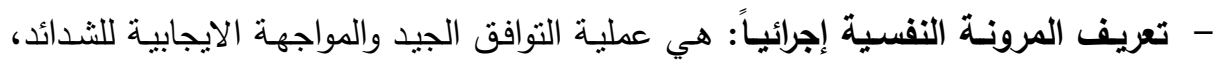

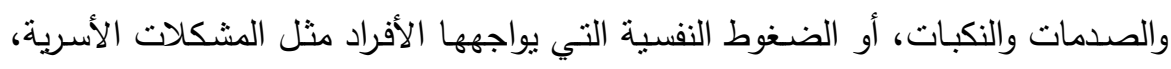

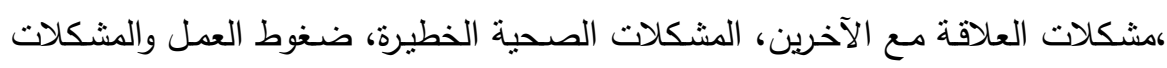

المالية.

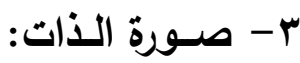

أ- الــات لغـة: وذات الثيء نفس الثيء عينه وجوهره فهذه الكلمة لغوياً مرادفة لكلمة النفس والثيء، ويعتبر الذات أعم من الثخص لأن الذات نطلق على الجسم وغيره

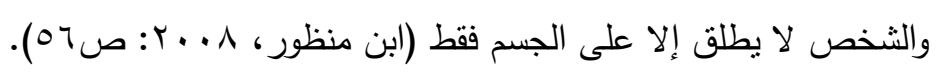

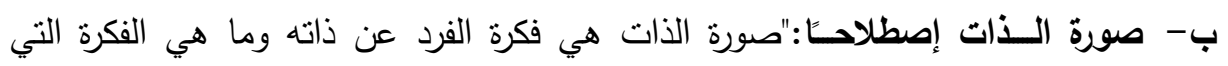

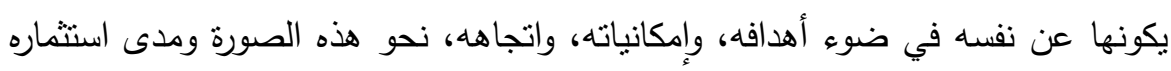

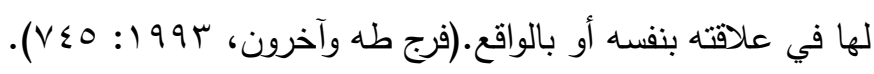

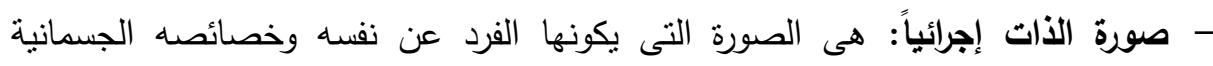
والعقلية والصورة التى تتتج من تفاعلاته وعلاقاته وسلوكه مع الآخرين. 
ع - الإعاقـة الحركيـة: المعاقون حركيا هم أولئك الأشخاص الذين يعانون من حالة عجز عظيمه أو عضلية أو عصبية أو حالة مرضيه مزمنة تحد من قدرتهم على استخدام

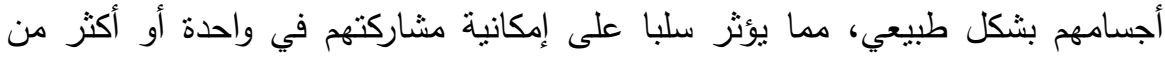

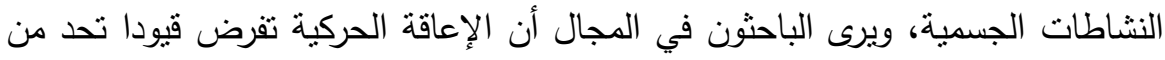

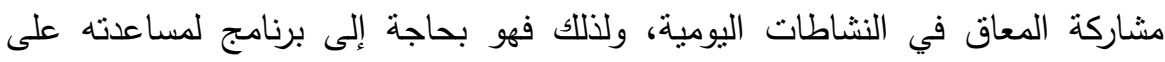
تخطى الحواجز النفسية، والحواجز المادية التي تتجم عن الإعاقة. (زكريا أحمد الثربيني ،

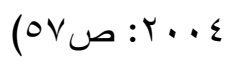

\section{- تعريف الإعاقة الحركية إجرائياً:}

الإعاقة هى فقد الفرد لجانب كبير من قد ارته لأداء أدواره المختلفة بسبب مجموعة من الإنبات متداخلة من الأسباب، والتي تخلف آثار سلبية من قلق وخوف، مما يسنوجب التدخل لتأهيله واستثمار ما تبقى من قدراته لتحقيق التكيف مع المجتمع من جديد. ه-الأجهزة التعويضية والأطراف الصناعية: يفهر من معنى هذه مانه الكلمات بأنها مرتبطة بمساعدة الإنسان عما فقده من قدرة أو أطراف بأجهزة تقوم أو تساعد على انجاز ما تقوم بيه الأطراف الطبيعية بقدر الإمكان.

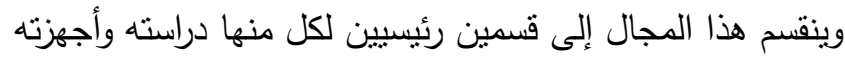
أ- الأجهزة التعويضية: هي أجهزة تعوض بقدر الإمكان القصور وعدم القدرة الكاملة للوظيفة

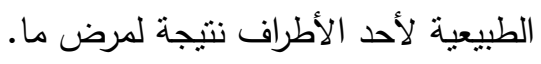

ب- الأطراف الصناعية :تعد الأطراف الصناعية هي البدائل الوظيفية للجزء الناقص من طرف مبتور، ويمكن أن تمند في اتجاه الجسد لتدعيم احد المفاصل التشريحية أو التحكم فيه ويتم تعليق الأطراف الاصطناعية في جسم المريض بوسائل شتى من بينها تعليقها في

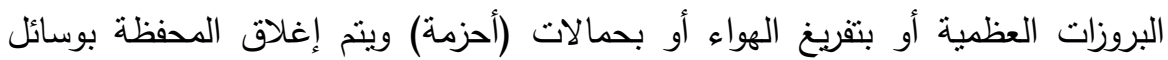
مختلفة منوافرة مثل المحبس (السدادة) وجعله على هيئة نصفين. (عدنان إبراهيم -تاج

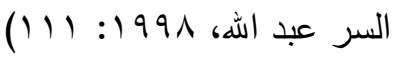


- تعريف الأجهزة التعويضية إجرائياً: هي أجهزة تعويضية تعد من البدائل للجزء الناقص من

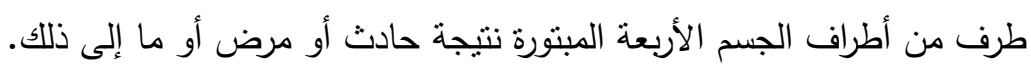

\section{السواسائس الساريخة}

تمثلت الاراسات السابقة في ثلاث محاور:

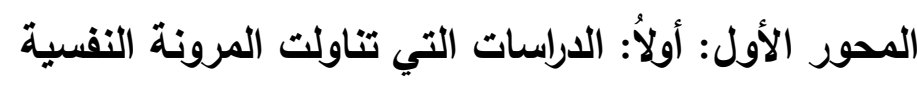

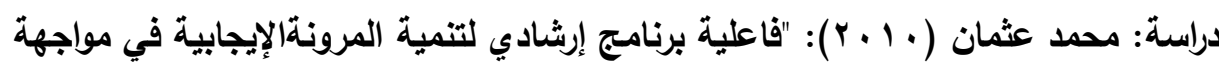
أحداث الحياة الضاغطة لاى عينة من الثباب". هدفت الاراسة: - إلقاء المزيد من البحث حول مفهوم المرونة النفسية الإيجابيةresilience متعدد المعاني والأبعاد والوصول إلى مكوناته الرئيسية.

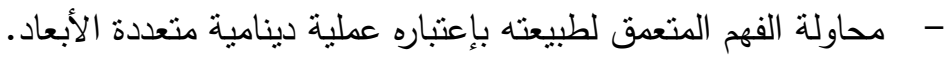

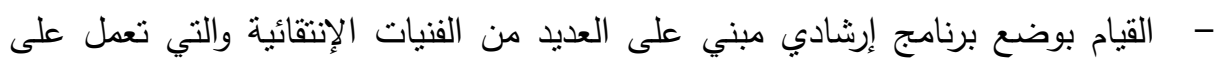

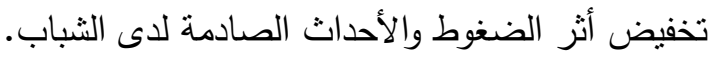
عينة الاراسة:

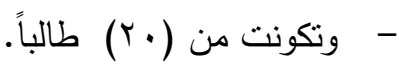

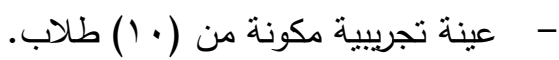
- - ضابطة مكونة من (•) طلاب بالفرقة الرابعة بجميع الثعب الأدبية والعلمية بكلية التربية بجامعة عين شمس. أدوات الدراسة: الته بجة - مقياس المرونة النفسية الإيجابية لدى الثباب (إعداد الباحث). - - مقياس أحداث الحياة الضاغطة لدى الثباب (إعداد الباحث). - برنامج إرشادي نفسي لتتمية المرونة النفسية الإيجابية (إعداد الباحث). 


\section{نتائج الاراسة:}

- فعالية البرنامج الإرشادي المستخدم ودوره في تتمية المرونة النفسية الإيجابية لدى افراد المجموعة التجريبية من الثباب الجامعي. - - - مفض الأحداث الضاغطة لايهم. - وقد استمرت فعالية البرنامج الإرشادي المستخدم حتى بعد انقضاء جلساته الإرشادية ومرور أكثر من شهر عليه، حيث قيست استجاباتهم على مقياس المرونة النفسية الإيجابية

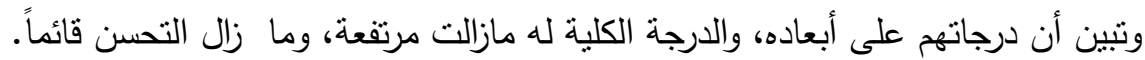

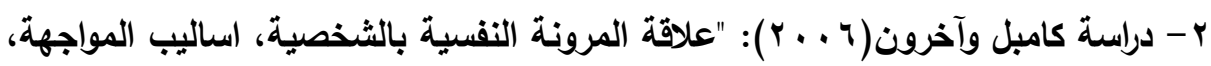
والاعراض النفسية لاى الشباب".

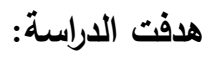
- التعرف على استجلاء العلاقة محتملة الوجود بين المرونة النفسية وكل من سمات

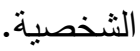
- التعرف على أساليب المواجهة والاعراض النفسية المرضية لدى الثباب الجامعى. عينة الدراسة: - تتكون من (r I I ) طالباً وطالبة من جامعة ولاية سان دييجو .

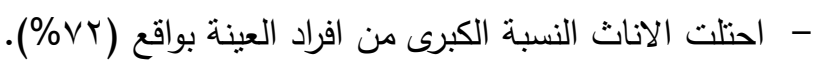

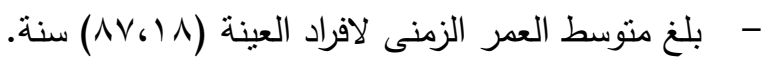
أدوات الاراسة: - ألغ موسط - مقياس كونر - ديفيدسون للمرونة الايجابية . - مقياس المواجهة للمواقف الضاغطة. - - استنيان صدمات - الطفولة - الثكل المختصر. - - ماسنبيان العوامل الخمسة للشخصية . نتائج الاراسة: - مeuroticism وجود علاقة إرتباطية سالبة بين المرونةالإيجابية والعصابية - 
- توجد علاقة إرتباطية موجبة بين المرونة الإيجابية وكلا من الانبساطية Extroversion

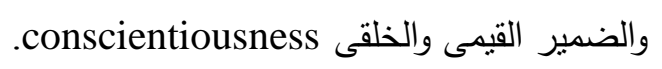

- إن المرونةالإيجابية تعد وسيطا يربط بين الاساءة والاهمال والقسوة فى الطفولة (كالاهمال

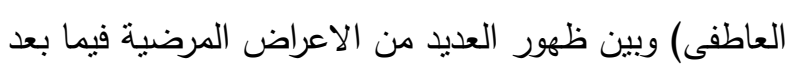

المحـور الثـاني:دراسات تناولت صـورة الـذات لاعى المعاقين جسمياً: سوف يتتاول في هذا صورة الذات من خلال عرض(0) دراسات ميدانية حول المعاقين جسمياً. دراسة "فتحية عبد الله منقوش" ( ( . ب): هدفت الدراسة: - - ملكثف عن العلاقة بين مفهوم الذات لدى المعاقين حركياً في اليمن. - التعرف على سمات شخصياتهم. عينة الدراسة:

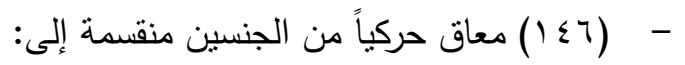

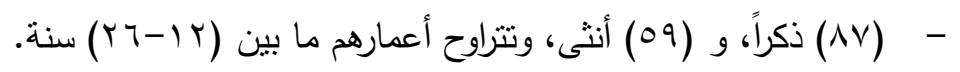

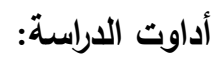

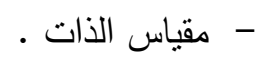

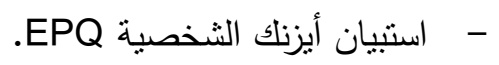
نتائج الدراسة:

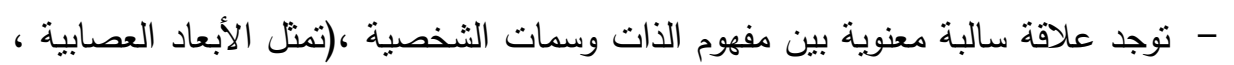
والذهانية ،والانطوائية / الانبساطية)

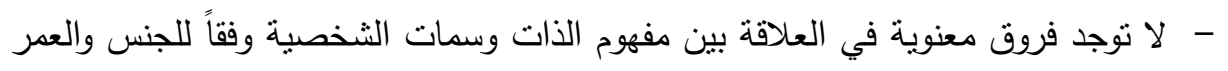
ونوع الإعاقة وسبب الإعاقة.

- توجد فروق معنوية في العلاقة بين مفهوم الذات وسمات الثخصية وفقاً للمستوى ونالإعل التعليمي. 
دراسة:(Sarah,2007) :المقارنة بين بتر الأطراف المخطط لها والناتجة عن الأمراض ويتر الأطراف الناتجةعن الحروب والحوادث.

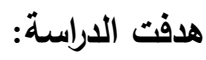
- المقارنة بين بتر الأطراف المخطط لها والناتجة عن الأمراض وبتر الأطراف الناتجة عن

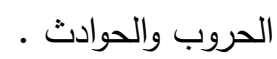

نتائج الاراسة: - أن البتر الناتج من الحروب والحوادث يتبعه درجة عالية من ظهور اضطراب ما بعد

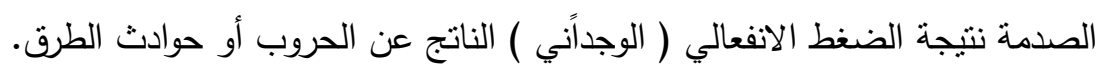

المحور الثالث: الدراسات التي تتاولت البرامج التأهيلية لمستخدمي الأجهزة التعويضية جسمياً:

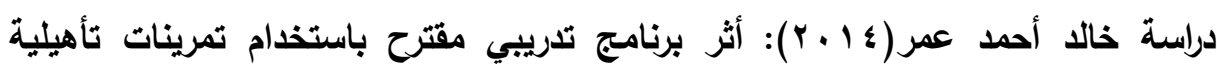

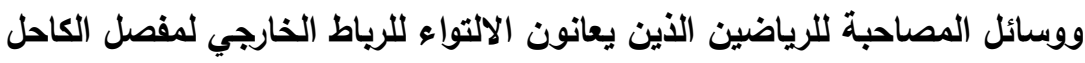

هدفت الاراسة:

- التعرف على تصميم برنامج بإستخدام تمرينات تأهيلية ووسائل المصاحبة للرياضين الذين

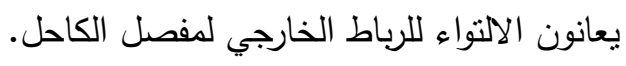

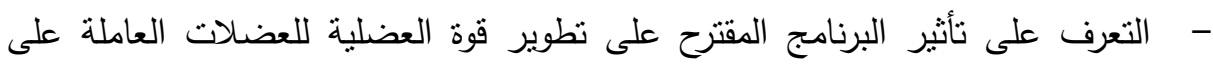

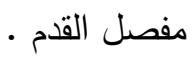
أدوات الدراسة: استخدم الباحث المنهج التجريبي:

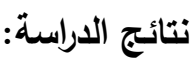
- -

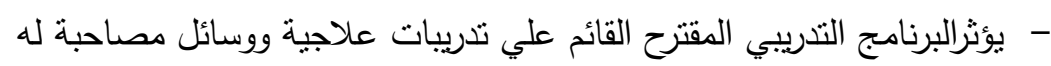

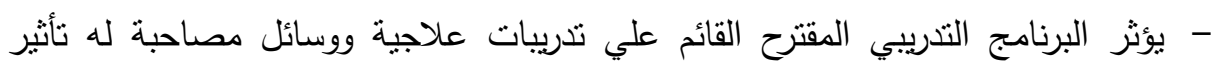
إيجابي على تطوير قوة العضلات القابضةالرياضيين الذين يعانون بإلتواء. 
دراسة: فريدمان ولورانس (Friedma , Lawrence 2002 ): العلاقة بين الوالدين وتأثيرها على ميل الابناء المعاقين حركيا للانبساط وزيادة التوافق النفسي والاجتماعي لديهم

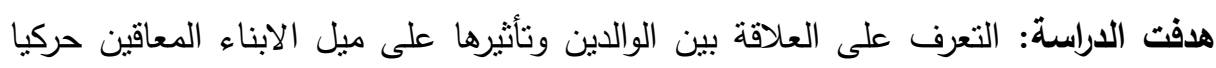
للانبساط وزيادة التوافق النفسي والاجتماعي لديهم. عينة الدراسة: ؟ ؟ طفل معاق حركيا واسرهم.

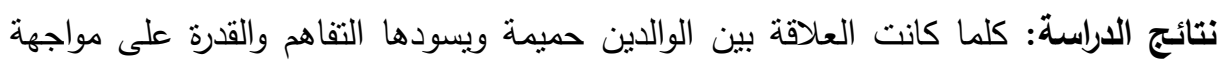

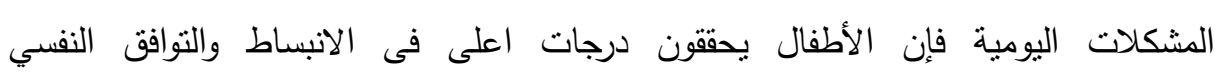
والاجتماعي. تعقيب: - اهتمت دراسات المحور الأول المرتبط بالمرونة النفسية لمبتوري الأطراف حيث تتوعت

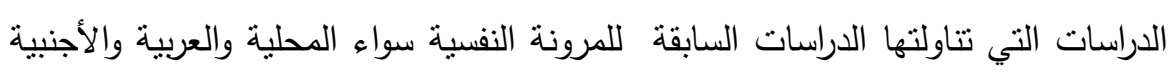
حيث تتاولت المرونة النفسة بصفة عامة، في حد علم الباحث لا نوجد دراسات تطرقت للمرونة النفسية عن الإعاقة الجسدية. - اهتمت دراسات المحور الثاني المرتبط بصورة الذات لاى المعاقين جسميا: حيث تتوعت الإعتة الدراسات التي تتاولتها الدراسات السابقة لصورة الذات المعاقين بصفة عامة سوراء الصاء المحلية

$$
\text { والعربية والأجنبية. }
$$

- اهتمت دراسات المحور الثالث المرتبط بالناحية البرامج التأهيلية الخاصة بالمعاقين حيث تتوعت الدراسات التي تتاولتها الدراسات السابقة البرامج التأهيلية الخاصة بالية بالمعاقين بصفة عامة سواء المحلية والعربية والأجنبية. أما عن الأطر النظرية التي اعتمدت عليها الدراسات فكان التركيز على العديده من التهاء النظريات منها، تطبيق نظريات المرتبطة بالمرونة النفسية (نظرية رتثاردسون، ونظرية المرونة النفسية، نظرية الأنا) في معمظم دراسات المرونة النفسية الثخصية، وتطبيق نظريات ( الثخصية والسلوكية المعرفية ) واستفاد الباحث من بعض هذه النظريات في دراسته 


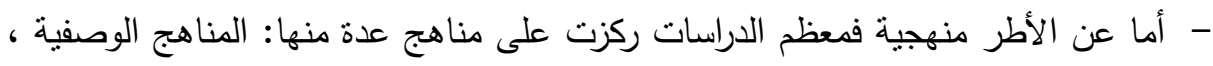
المنهج الكمي، المنهج المقارن، المنهج الوصفي التحليلي، التجريبي، المنهج الثنبه تجريبي، المنهج الوصفي الارتباطي.

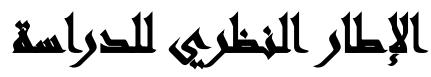

ومن النظريات التى حاولت الإسهام فى تفسير عملية المرونة النفسية، نظرية رتشاردسون

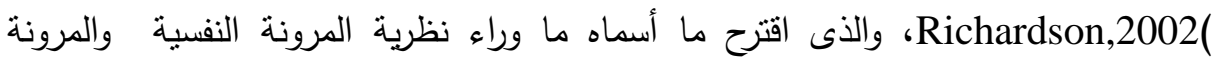
النفسية ( الارتدادية، والتى تطورت على مدار ثلاث موجات مختلفة من أبحاث المرونة

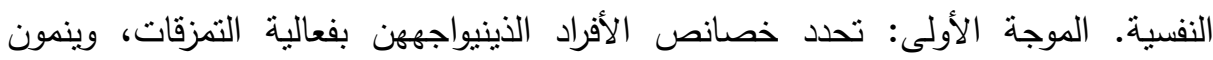
منخلالها. والموجة الثانية: تفحص العملياتالتى يكتسب الناس من خلالها هذه الخصائص. والموجة الثالثة: هى التعرف على المرونة النفسية الفطرى، وقدرتتا على النمو والتطور .

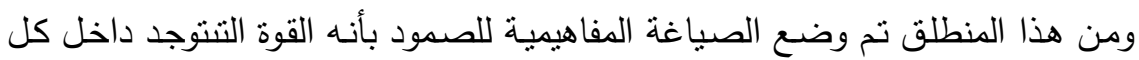

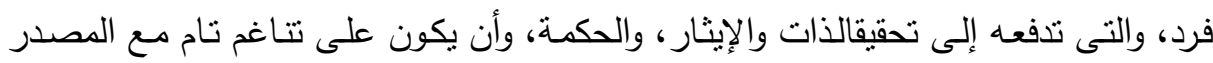

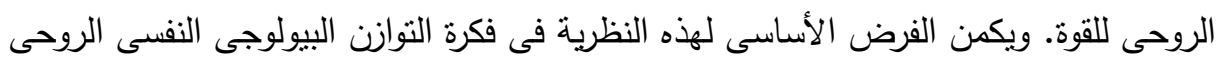

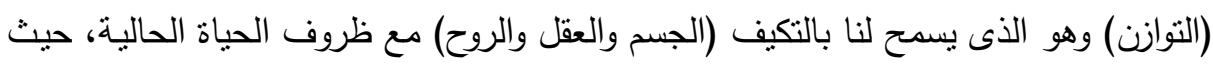

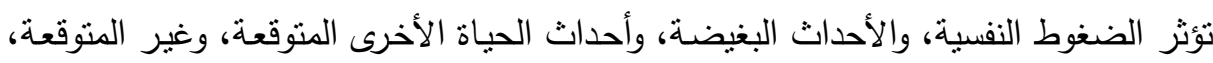
أو متطلبات الحياة العاجلة فى قدرتتا على التكيف، ومواجهة مثل هذه الأحداث في الحياة

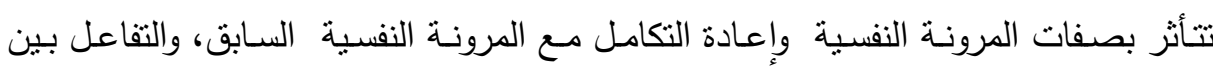
الضغوط النفسية اليومية والعوامل الوقائية.

وقد أوضح Matthew, بعض العوامل التي نساعد على استمرارية المرونة 2002

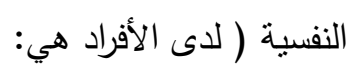

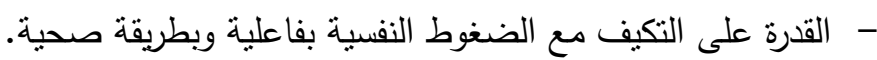

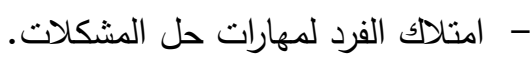
- اعتقاد الفرد بوجود شيء يمكن القيام به للسبطرة على الششاعر الحادة والتكيف مع الظروف الطارئة. 
- الاتصال والترابط مع الآخرين مثل العائلة أو الأصدقاء.

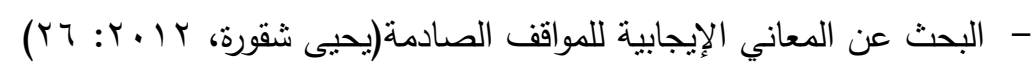

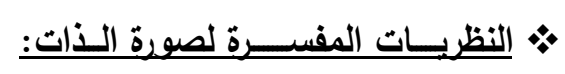

1-النظــية السلوكيـة: نتظر المدرسة السلوكية إلى صورة صورة الذات على أنه سلوك متعلم من البيئة التى يعيش فى وسطها الفرد، تحت شروط التدعيم الإيجابى والتدعيم

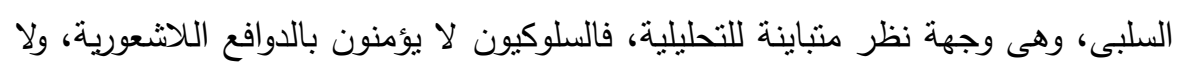

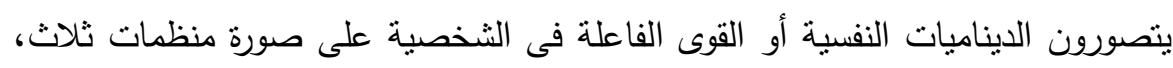

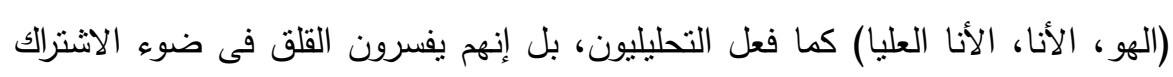

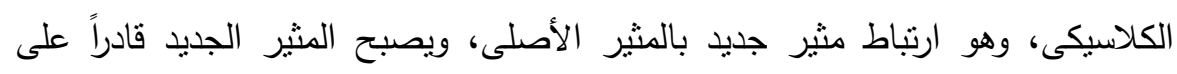

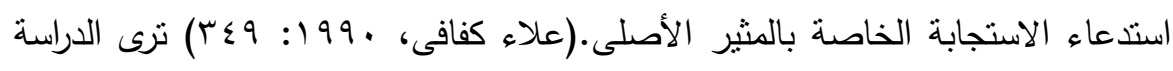

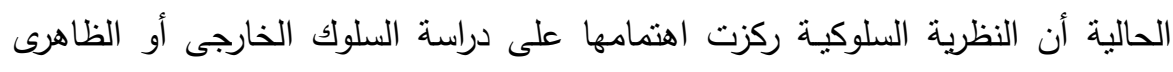
اعتماداً على المثير والاستجابة. r-النظـرية المعرفــة: تقوم النظرية المعرفية على فكرة أن الانفعالات التى يبديها الناس، إنما هى ناتجة عن طريقتهم فى التفكير، ولهذا فهى ركزت على عدم عقلانية التفكير

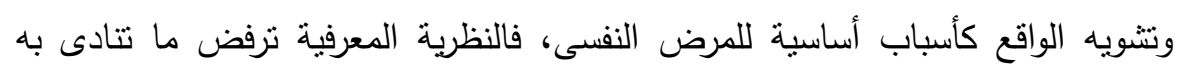

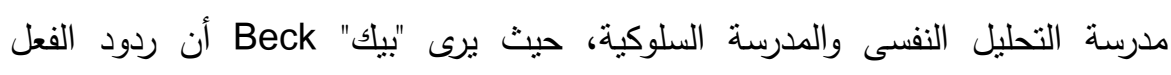
الانفعالية ليست استجابات مباشرة ولا تلقائية للمثير الخارجى وإنما يجرى تحليل المثيرات

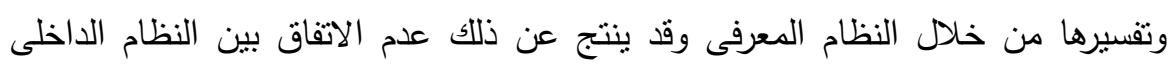

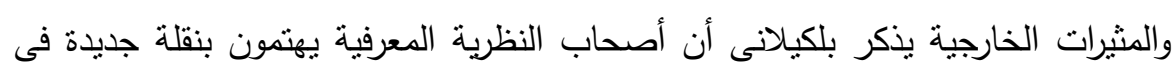

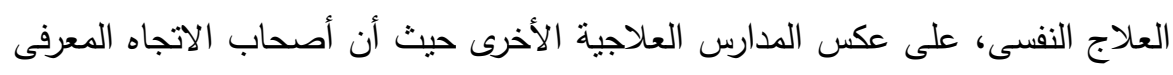

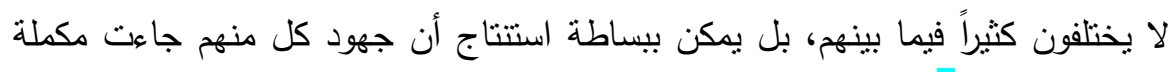
لجهود الآخرين ـ. (· نهى مصطفى يوسف الحموي ، 997 (1) ) 


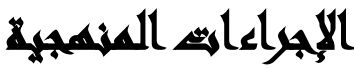

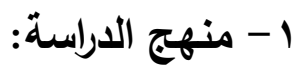

المنهج الوصفي: اعتمد الباحثون على المنهج الوصفي التحليلي الذي يعمل على وصف الظاهرة المدروسة وتحليل جوانبه أبعادها المختلفة وصفا كميا وكيفيا والتعرف على العوامل لفيل

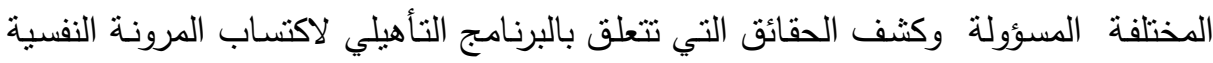
وأثثر على صورة الذات لدى مستخدمي الاجهزة التعويضية. المنهج شبه التجريبي: يعد المنهج شبه التجريبي (الامبريقى) أحدث مناهج البحث وأكثرها دقة وأثندها صعوبة وتعقيداً، ويتم فيه جمع البيانات على نحو يسمح باختبار عدد من الفروض

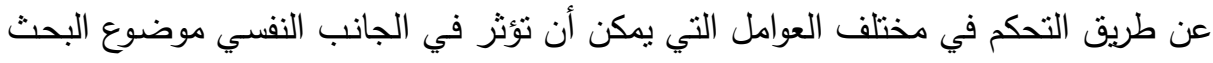
والوصول بذلك إلى إيجاد تفسير لمشكلة البحث من خلال تحليل النتائج.

r - نوع الدراسةة: تعد هذه الدراسة من الدراسات الوصفية المقارنة التي تسعى إلى وصف

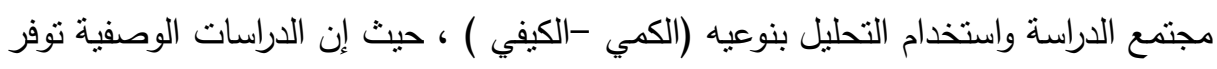

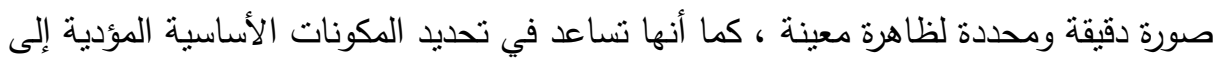
وصف وتتخيص وتحليل الظواهر في المجتمع للكثف عن فاعلية برنامج تأهيلي لاكتساب المرونة النفسية واثره على صورة الذات لدى مستخدمي الاجهزة التعويضية. أما مصدر البيانات فقد تم الحصول عليها من مصدرين هما: أ - المصادر الثانوية: حيث اتجه الباحث في معالجة الإطار النظري للاراسة إلى مصادر

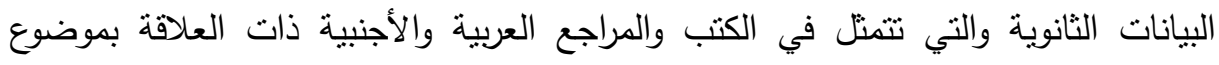

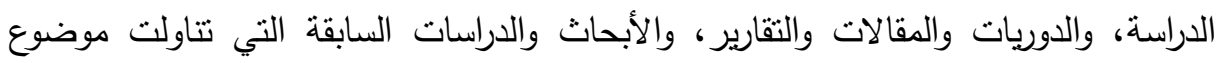
الدارسة، والبحث والمطالعة في مواقع الإنترنت المختلفة. ب - المصادر الأولية: وتتمثل في جمع البيانات الأولية ميدانياً. الأدوات المستخدمة:

$$
\text { 1-استمارة البيانات الأولية (إعداد الباحثون) }
$$

$$
\text { المجلد الخامس والأربعون، الجزء الثالث، مارس } 19 \text { ـ ب }
$$


تهدف هذه الاستمارة إلي جمع معلومات عن مستخدمي الأجهزة التعويضية.

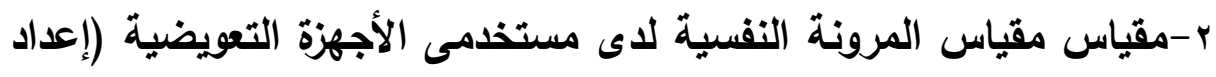

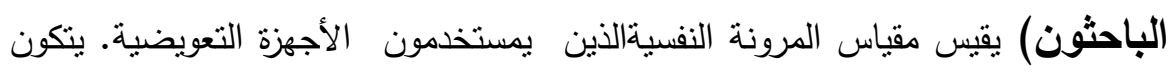
المقياس من ثلاث ابعاد كالآتي(القدرة على تكوين علاقات إجتماعية مع الآخرين - القدرة

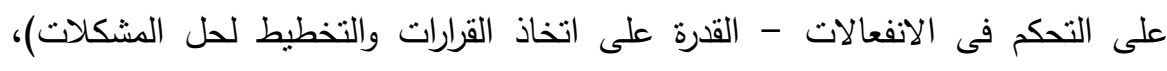

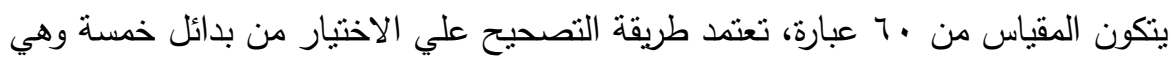

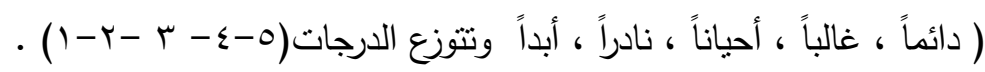

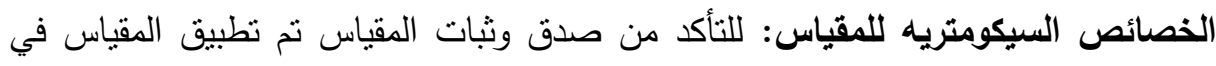

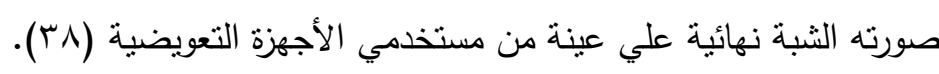

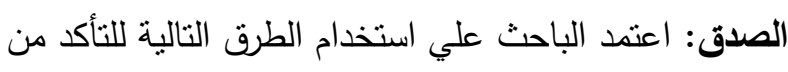

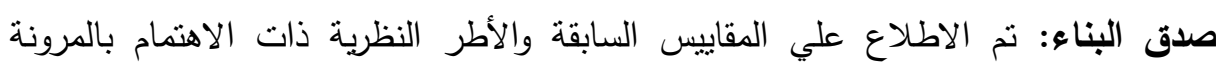

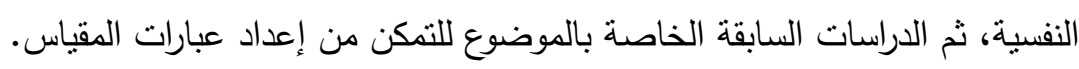

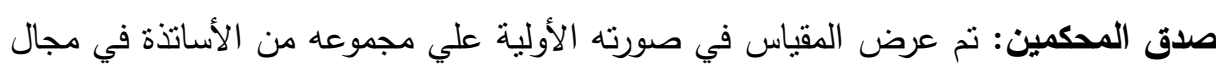

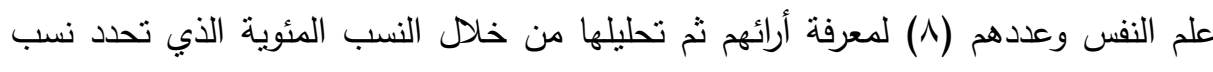

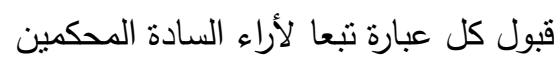

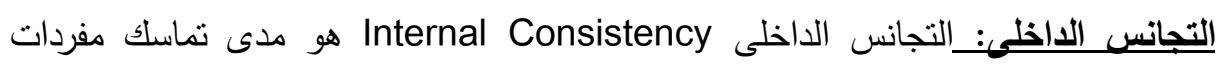

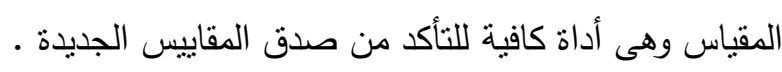

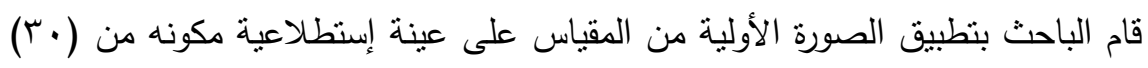

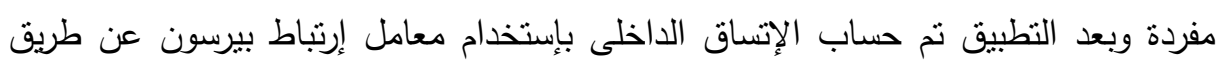

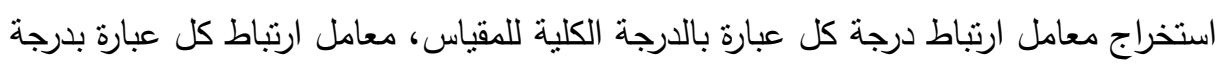

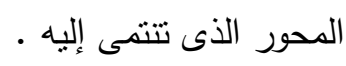


مجلة العلوم البيئية

معهد الدراسات والبحوث البيئية - جامعة عين شمس

جدول ( ) : معاملات ارتباط التوافق بين درجات كل عبارة والدرجة الكلية للمقياس

\begin{tabular}{|c|c|c|c|c|c|c|c|c|}
\hline الدلالة & الارتباط & العبارة & الدلالة & الارتباط معامل & العبارة & الدلالة & الارتباط معامل & العبارة \\
\hline$\cdot, \cdots$ & $* *$, , IVV & $\leq 1$ & $\cdot, \ldots 1$ & $* *, 0 \vee 1$ & YI & $\cdot,+1$. & $* *$, , $\leqslant$ ४ & 1 \\
\hline$\cdot, \ldots$ & $* *, \vee \vee q$. & $\varepsilon r$ & $\cdot, \cdots$ & $* *, 7 \mu \mathrm{V}$ & $r r$ &., 010 & $*$. , $\leqslant$ r $q$ & $r$ \\
\hline$\cdot, \ldots$ & $* *, \vee \vee \backslash 7$ & $\leq r$ & $\cdot, \cdots$ & $* *, \wedge \wedge$ & $r r$ & $\cdot, \cdot Y I$ & $* *,, \leqslant 19$ & $r$ \\
\hline$\cdot, \ldots$ & $* *, 74 r$ & $\leq \varepsilon$ & $\cdot, \ldots$ & $* *, V \bullet r$ & $r \leq$ & $\cdot, \ldots 9$ & $* *, \leq 4 \wedge$ & $\varepsilon$ \\
\hline$\cdot, \ldots$ & $* *, T \vee \mu$ & $\leq 0$ & $\cdot, \ldots$ & $* *, \quad \neg \leqslant V$ & ro & $\cdot, \ldots$ & $* *, \Upsilon \wedge \varepsilon$ & 0 \\
\hline$\cdot, \ldots$ & $* *, 7 r 4$ & $\leq 7$ & $\cdot, \ldots$ & $* *, \vee \vee 0$ & ry &., 019 & *., \&YY & 7 \\
\hline$\cdot, \ldots$ & $* *,, \vee \sim ч$ & $\leq V$ & $\cdot, \cdots$ & $* *,, \curlyvee \wedge \wedge$ & $r V$ & $\cdot, \ldots 1$ & $* *,, \diamond \wedge r$ & $v$ \\
\hline$\cdot, \ldots$ & $* *, \vee \backslash 19$ & $\leqslant \wedge$ & $\cdot, \ldots$ & $* *,, V \cdot r$ & $r \wedge$ & $\cdot, \ldots r$ & $* *, 001$ & $\Lambda$ \\
\hline$\cdot, \ldots$ & $* *, \wedge 9 \mu$ & $\leq 9$ & $\cdot, \cdots$ & $* *, \wedge \leq V$ & rq & $\cdot, \ldots$ & $* *, \nearrow, \varepsilon$ & 9 \\
\hline$\cdot, \ldots$ & ***, • צ & 0. & $\cdot, \ldots$ & $* *, \vee \vee \wedge \neg$ & $r$. & $\cdot, \cdots$ & $* *, V, \ldots$ & 1. \\
\hline$\cdot, \ldots$ & $* *,, \diamond \wedge 9$ & 01 &,,$\ldots$ & $* *,, \vee \ldots$ & $M$ & $\cdot, \ldots$ & 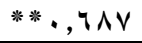 & 11 \\
\hline$\cdot, \ldots$ & $* *, \Upsilon \vee$. & or & $\cdot, \ldots$ & $* *, \wedge$ Y & rr & $\cdot, \ldots$ & $* *, \vee \vee \diamond 0$ & Ir \\
\hline$\cdot, \ldots$ & $* *, \vee \vee ৭$. & or & $\cdot, \cdots$ & ***, & $r r$ & $\cdot, \ldots 1$ & $* *, \diamond \vee q$ & ir \\
\hline$\cdot, \ldots$ & $* *, \wedge \wedge 9$ & $0 \leq$ & $\cdot, \ldots$ & $* *, v \leq 9$ & $r \varepsilon$ & $\cdot, \ldots$ & $* *, \vee v \leq 7$ & $1 \leq$ \\
\hline$\cdot, \ldots$ & $* *, \wedge \div V$ & 00 & $\cdot, \ldots$ & $* *, 7 \leq 1$ & ro & $\cdot, \ldots$ & $* *, Y r r$ & 10 \\
\hline$\cdot, \ldots$ & $* *, \vee \vee \backslash 7$ & 07 & $\cdot, \cdots$ & $* *, \wedge \leq r$ & r & $\cdot, \ldots$ & $* *, 710$ & 17 \\
\hline$\cdot, \ldots$ & $* *, \vee \vee Y \leq$ & $\Delta V$ & $\cdot, \ldots$ & $* *, 710$ & $r v$ & $\cdot, \ldots 1$ & $* *, 000$ & iv \\
\hline$\cdot, \ldots$ & $* *, \vee \vee \diamond \leq$ & $\Delta \wedge$ & $\cdot, \ldots$ & $* *, \Upsilon Y 1$ & $r \Lambda$ & $\cdot, \ldots$ & $* *, \vee \vee 90$ & 11 \\
\hline$\cdot, \ldots$ & $* *, \vee V \Psi \leq$ & 09 & $\cdot, \ldots$ & $* *, \vee \vee \vee ५$ & $r 9$ & $\cdot, \ldots$ & $* *$, , IY & 19 \\
\hline$\cdot, \ldots$ & $* *, \neg \wedge$. & 7. & $\cdot, \ldots$ & $* *, \wedge 91$ & 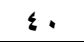 & $\cdot, \ldots$ & $* *, \wedge \leq q$ & $r$. \\
\hline
\end{tabular}

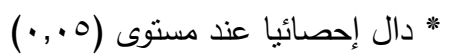

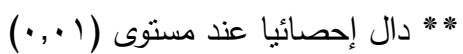

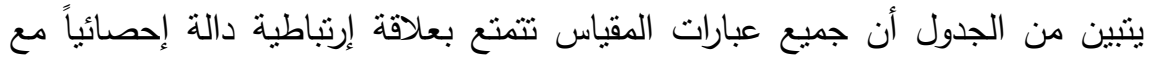

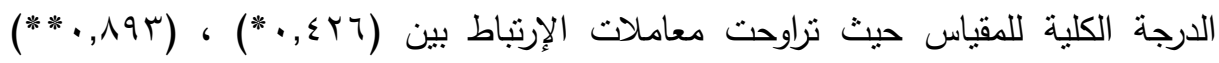
وجميعها دالة عند مستوى دلالة (1 ( , ) ، (0. . • ) والمقياس يقيس ما وضع من أجله صدق المحك الخارجي: تم مقارنة درجات المقياس الحالي باختبار أخر ثثبت صدقة وثباته من قبل، وهو مقياس المرونة النفسية ، فطبق الباحثون المقياس علي نفس العينة ثم حساب معامل الارتباط بين درجات المقياسين الذي بلغ (ع 90. .). صدق التمبيز: طريقة المقارنة الطرفية بين أعلي هب\%من الدرجات وأقل هب\% من الدرجات 
ثبات المقياس: اعتمد الباحث علي الطرق التالية ( إعادة النطبيق بلغت قيمة الثبات ؟90.

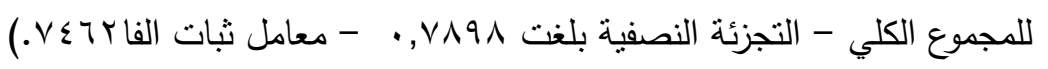

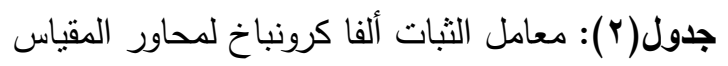

\begin{tabular}{|c|c|c|}
\hline مستوى الدلالة & قيمة معامل & 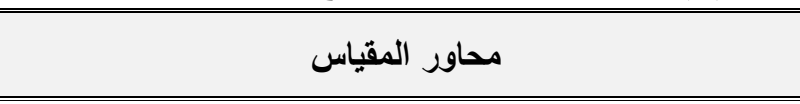 \\
\hline الة & $\cdot$, VOr & المحور الاول: القدرة على تكوين علاقات إجتماعية مع الآخرين \\
\hline دالة & $\cdot, \wedge \vee \varepsilon$ & المحور الثانى: القدرة على التحكم فى الانفعالات \\
\hline دالة & $\cdot, \wedge \leqslant q$ & المحور الثالث: القدرة على اتخاذ القرارات والتخطيط لحل الشكلات \\
\hline دالة & $\cdot, \wedge \leqslant 1$ & المقياس ككل \\
\hline
\end{tabular}

وفي ضوء نتائج معاملات الثبات لمحاور المقياس الثلاثة الموضحة بالجدول السابق، لم

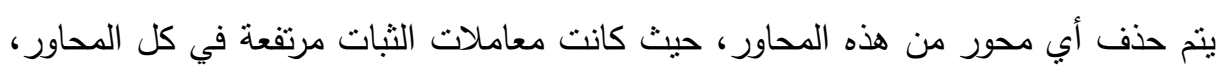

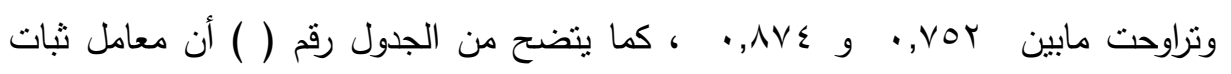

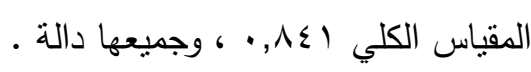

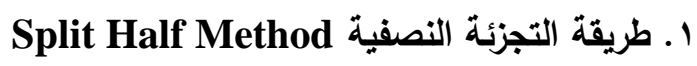

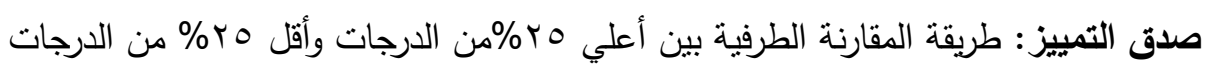

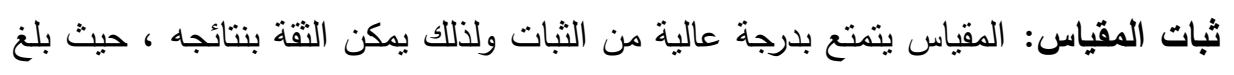

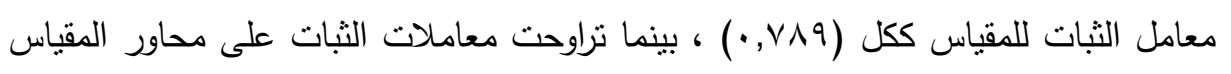

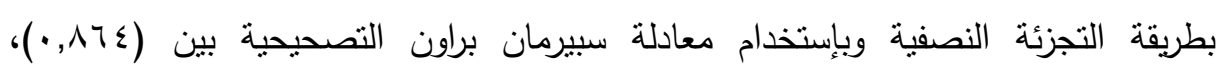

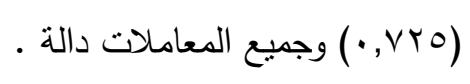

الاتساق الداخلي: نم حساب الاتساق الداخلي للمقياس عن طريق حساب دالة معامل الارتباط بين

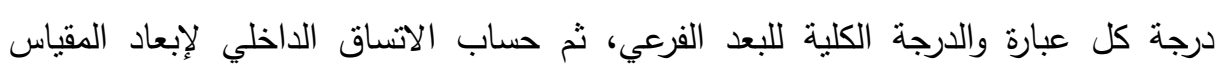
بحساب معامل الارتباط بين درجة كل بعد والدرجة الكلية للمقياس. ب-مقياس مقياس صورة الأات لاى مستخدمى الأجهزة التعويضية (إعداد الباحثون): يقيس مقياس صورة الذات الذين يمستخدمون الأجهزة التعويضية. يتكون المقياس من ثناث ابعاد كالآتي: ( صورة الذات الجسمى والثخصىى - صورة الذات

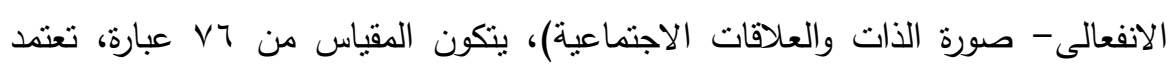


طريقة التصديح علي الاختيار من بدائل خمسة وهي ( دائماً، غالباً، أحياناً، نادراً، أبداً )

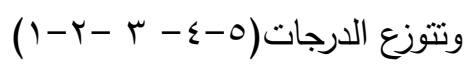

الخصائص السيكومتريه للمقياس: للنأكد من صدق وثبات المقياس تم تطبيق المقياس في

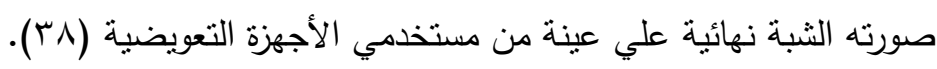

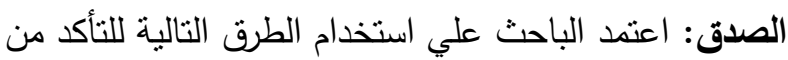
صدق البناء: نم الاطلاع علي المقاييس السابقة والأطر النظرية ذات الإنتمام بصورة الذات النات ،ثم الدراسات السابقة الخاصة بالموضوع للتنكن من إعداد عبارات المقياس. صدق المحكين: نم عرض المقياس في صورته الأولية علي مجموعه من الأساتذة في مجال

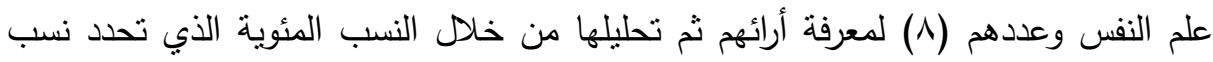
قبول كل عبارة تبعا لأراء السادة المحكمين.

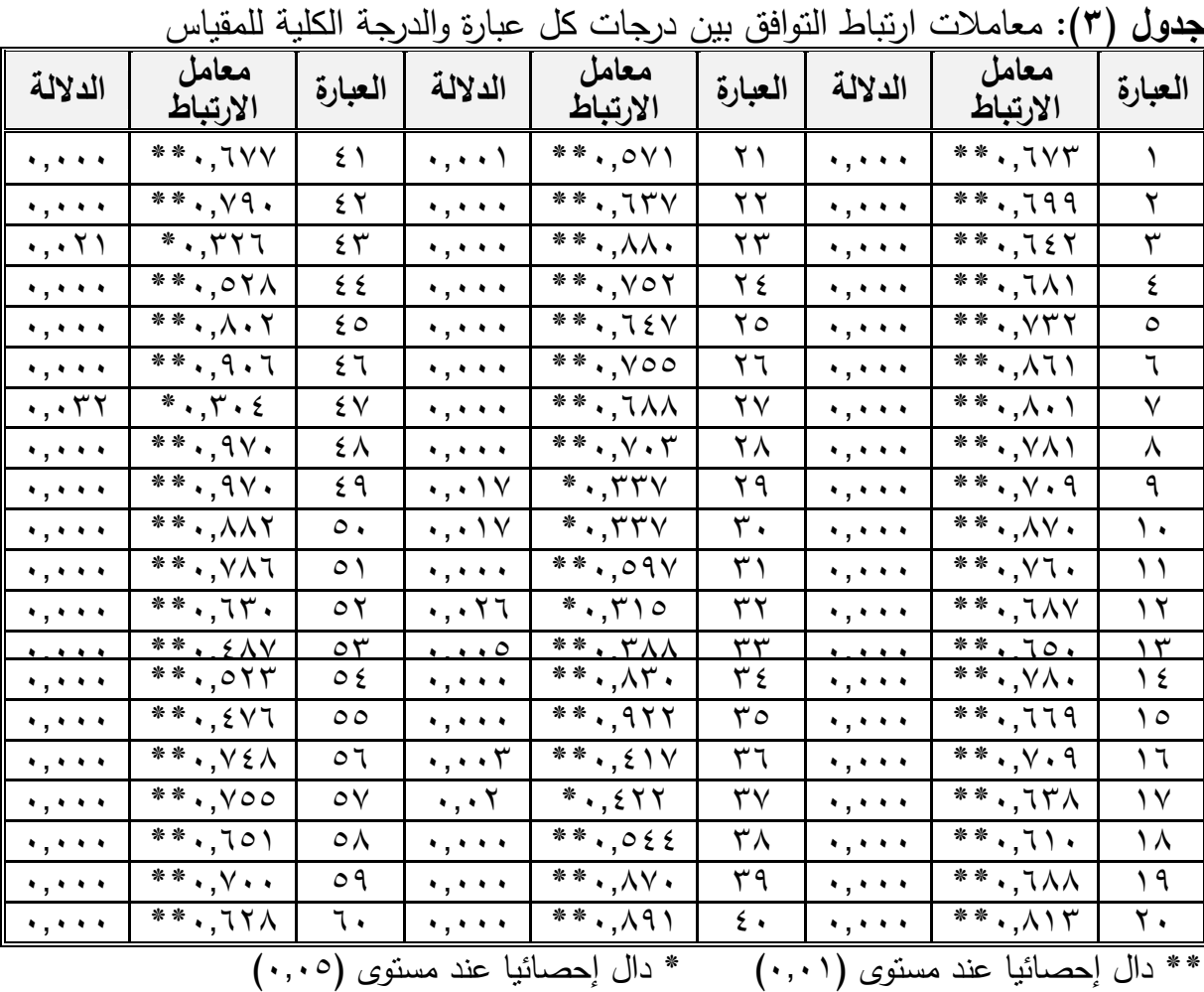


ينتين من الجدول أن جميع عبارات المقياس تتمتع بعلاقة إرتباطية دالة إحصائياً مع

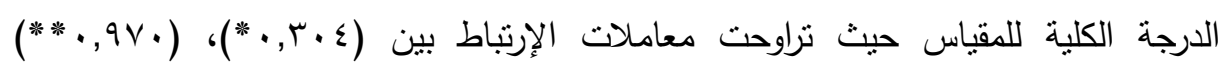

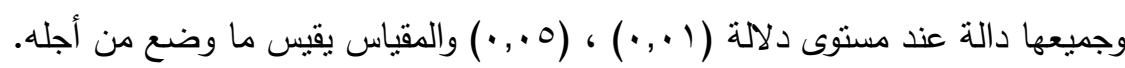

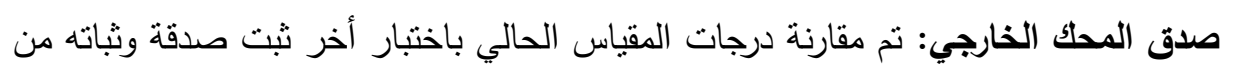

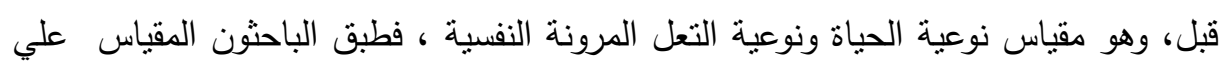

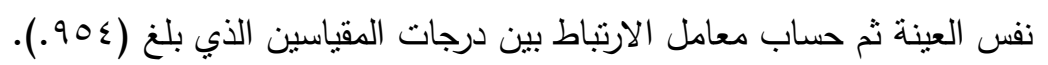

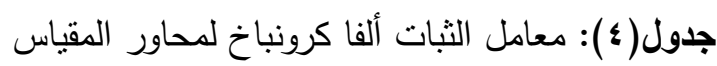

\begin{tabular}{|c|c|c|}
\hline مستوى الدلالة ( 1 +, •) & قيمة معامل الثبات & محاور المقياس \\
\hline دالة & $\cdot, \wedge \Sigma 1$ & المحور الاول: صورة الذات الجسمى والثخصى \\
\hline دالة &., 9.1 & المحور الثاني : صورة الذات الانفعالى \\
\hline دالة & $\cdot, \vee \vee 99$ & المحورالثالث :صورة الذات والعلاقات الاجتماعية \\
\hline دالة & $\cdot$, AVq & المقياس ككل \\
\hline
\end{tabular}

وفي ضوء نتائج معاملات الثبات لمحاور المقياس الثلاثة الموضحة بالجدول السابق، لم

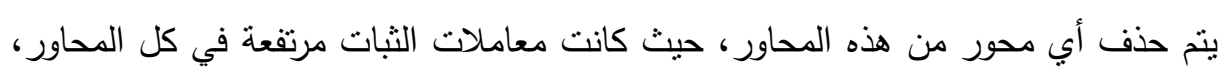

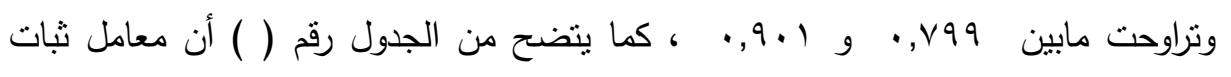

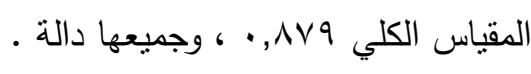

\section{:Split Half Method النصفيقة التجزئة النصفية}

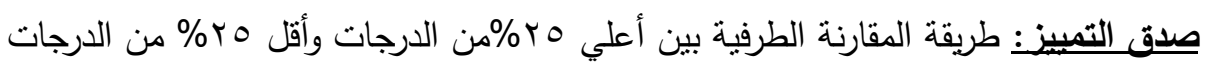

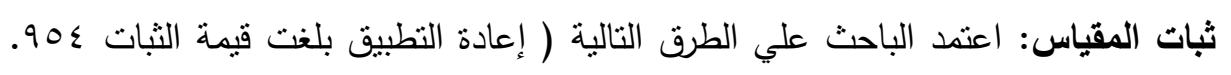

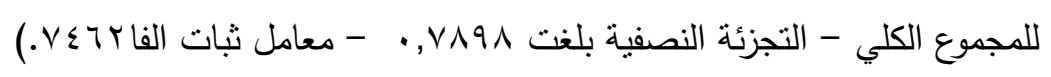
الاتساق الداخلي:تم حساب الاتساق الداخلي للمقياس عن طريق حساب معامل الارتباط بين

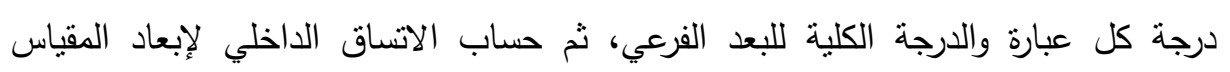
بحساب معامل الارتباط بين درجة كل بعد والدرجة الكلية للمقياس. من كل ما سبق تحقق الباحثّن من صدق وثبات المقياس. 
؛-البرنامج التأهيلي(إعداد الباحثنون): برنامج التأهيل المهنى للمعاقين: يهدف

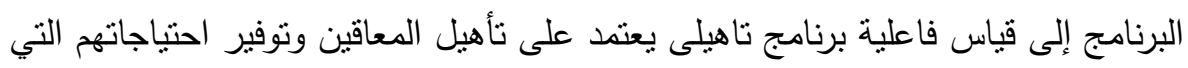

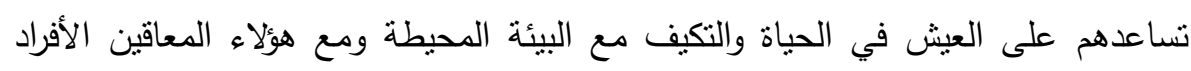

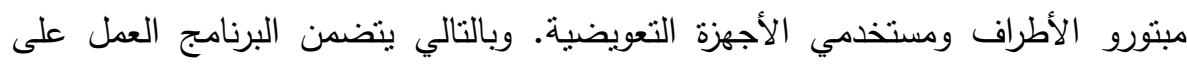
تحقيق الأهداف الإجرائية التالية: • • ت تمية روح الجماعة والتعاون لاى المعاقين. • • ارتفاع الروح المعنوية لدى المعاقين وتقبلهم النفسى لذواتهم كما هى.

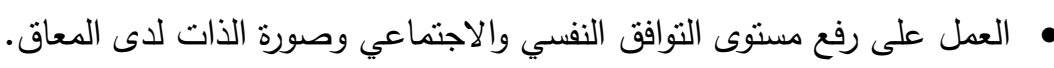

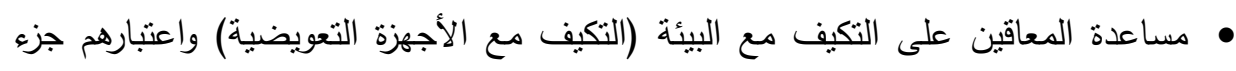

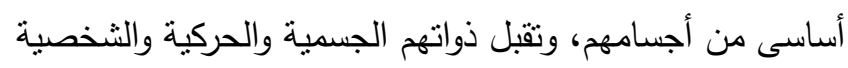

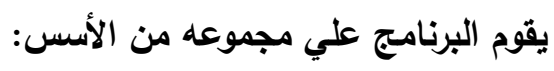
• الأسس العامة: الثبات النسبي للسلوك الإنسان ، الإنس ، مرونة السلوك الإنساني، السلوك الإنساني

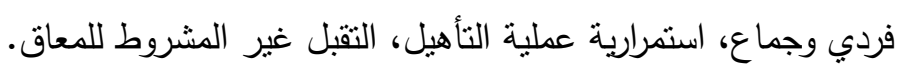

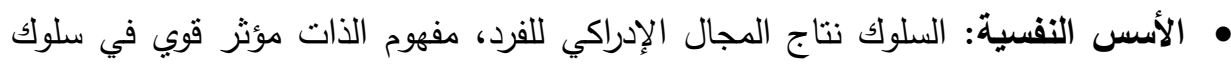

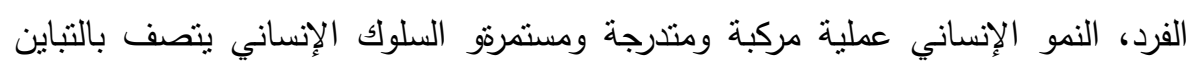

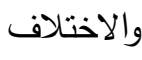

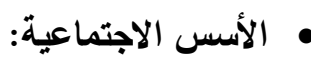

- - ملوك الفرد محكوم إلى حد بعيد بالتنظيمات الاجتماعية .

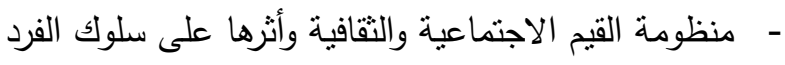

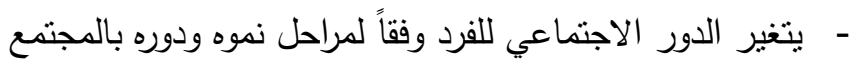
- - الإهتمام بالفرد كعضو في جماعة ،ة واستثمار مصادر المجتمع للمعاقين من خلال التأهيل

$$
\begin{aligned}
& \text { • • الأسس الأخلاقية: }
\end{aligned}
$$

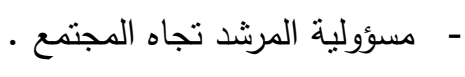

$$
\begin{aligned}
& \text { - مسؤولية المرشد نجاه المعاق }
\end{aligned}
$$


- استتد الباحث إلي إعداد برنامج تكاملي يعتمد علي انتقاء فنيات واستراتيجيات من عدة

$$
\text { نظريات ما يناسب العينة }
$$

تحكيم البرنامج التأهيلي: نقييم البرنامج من خلال عرض الباحث للبرنامج علي الأساتذة في مجال علم النفس عددهم (^)، وإجراء التعديلات اللازمة.

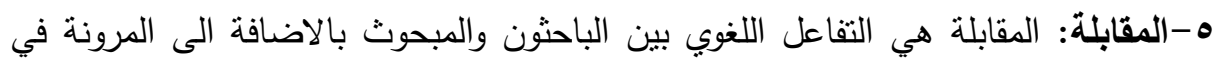

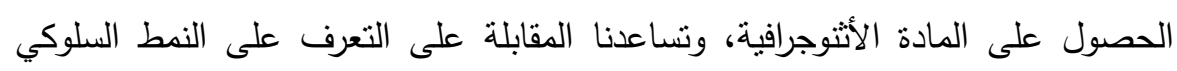

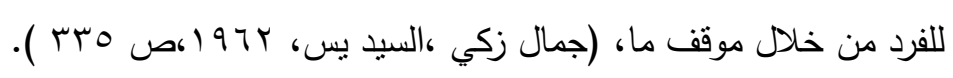

צ-الملاحظة: تعد الملاحظة والملاحظة بالمشاركة أداتان هامتان في علم الاجتماع ولماع والنفس

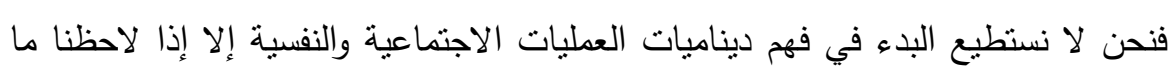

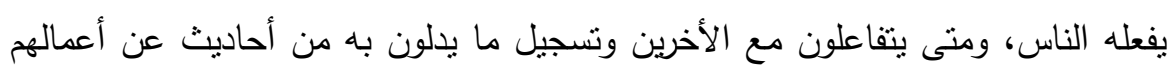

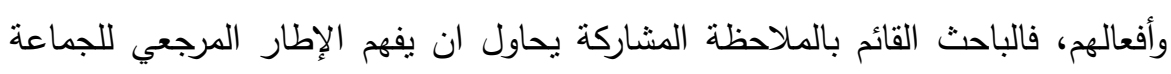

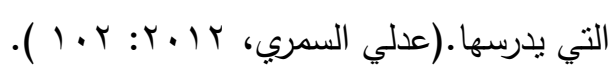

\section{هجالاهي القواسما}

المجال الجغرافي: طبق المقياسين والبرنامج على.مصنع الأطراف الصناعية والأجهزة التعويضية بشركة العبوات والمستلزمات الطبية إحدى شركات الثركة القابضة للأدوية أ-العينة : بأنها جزء من مجتمع يختار بطريقة علمية لتوفير بيانات عن مجتمع الدراسة

\section{العينة مقسمة إلي:}

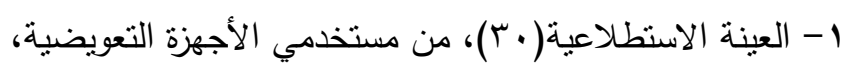

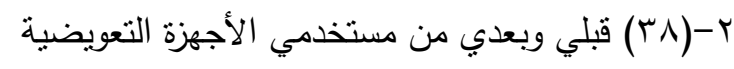

\section{المنائيج المهائية}

1-" توجد فروق ذات دلالة إحصائية بين متوسطات درجات المجموعة التجريبية في التطبيق

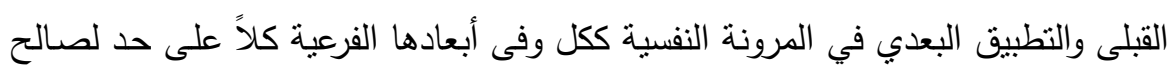

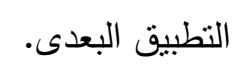


وللتحقى من هذا الفرض قام الباحث بإتباع الخطوات التالية:

ا ـ استخدام إختبار (ت) فى حالة عينتين غير مستقلنين Paired Samples T-Test وذلك فيلك للتعرف على معنوية تأثير البرنامج التأهيلى على المرونـة النفسية لدى مستخدمى الاجهزة

$$
\text { التعويضية. }
$$

r. حساب المتوسط الحسابى والانحراف المعيارى لكلاً من التطبيق القبلى والتطبيق البعدي .

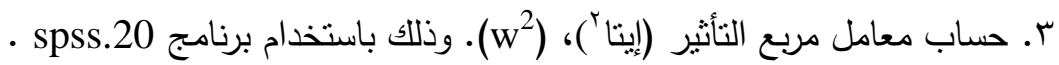

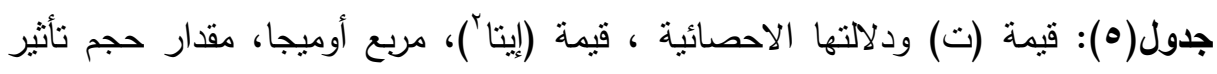

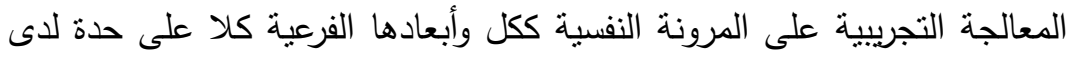
مستخدمى الاجهزة التعويضية في التطبيق البعدى

\begin{tabular}{|c|c|c|c|c|c|c|c|c|c|}
\hline \multirow{2}{*}{ 㤝高 } & \multirow{2}{*}{ 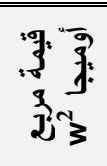 } & \multirow{2}{*}{ 䚄 可" } & \multirow{2}{*}{ : 공 } & \multirow{2}{*}{ 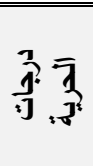 } & \multicolumn{2}{|c|}{ التبيق البعدي } & \multicolumn{2}{|c|}{ التبيق القبلى } & \multirow[t]{2}{*}{$\overline{\overline{7}} \overline{7} \overline{7}$} \\
\hline & & & & & r & tל & $\varepsilon$ & is & \\
\hline كبيرً & $\cdot, 941$ & $\cdot, 90$. & rד, rq & TV & $\Lambda, \Gamma r$ & $q \cdot, q \vee$ & $v, v_{0}$ & $\begin{array}{l}r q, \\
4\end{array}$ & الكوين علاقات القاتية \\
\hline كبيير & $\cdot, \wedge \leqslant \wedge$ & $\cdot, 9 \ldots$ & $|\Lambda, Y \wedge|$ & rv & 9,79 & $V \varepsilon, 0$. & 9,11 & $\begin{array}{l}\text { ru, } \\
\text { vit }\end{array}$ & الانتكمة فى لى \\
\hline كبيرً & • & $\cdot, 901$ & $r \uparrow, \wedge 90$ & TV & $0, Y \cdot T$ & $v_{0}, r_{9}$ & $\mathrm{~T}, \mathrm{VV}$ & $\begin{array}{l}r v, \\
r y\end{array}$ & التخاذ القرارات التشيط لحل \\
\hline كبيرً & •, $97 \varepsilon$ & $\cdot, 9 \vee V$ & $r q, q) \leqslant$ & rV & $17, \wedge \varepsilon$ & $r \varepsilon, \wedge V$ & $\underset{r}{r}, q$ & 11. & إلمقياسلى \\
\hline
\end{tabular}

وجود فروق ذات دلالة إحصائية عند مستوى دلالة ( ا •, ·) بين التطبيق القبلى والتطبيق البعدي للمجموعة التجريبية في المرونة النفسية ككل وجميع أبعادها المنمثلة في (القدرة 
على تكوين علاقات اجتماعية مع الاخرين، القدرة على التحكم فى الانفعالات، القدرة على

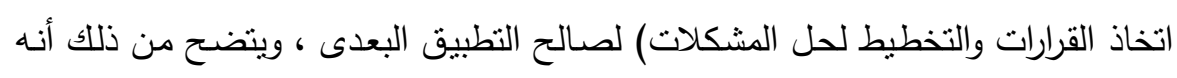

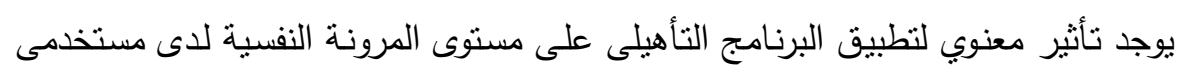
الاجهزة التعويضية.

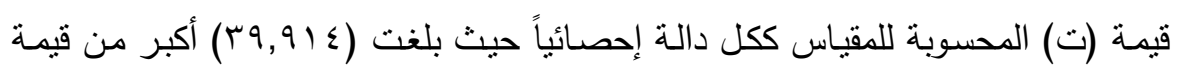

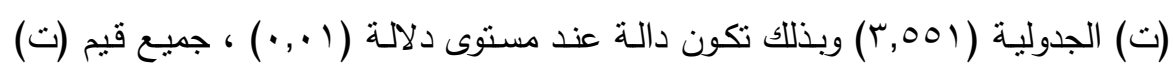

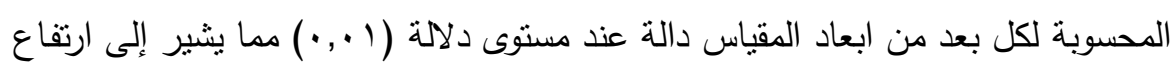

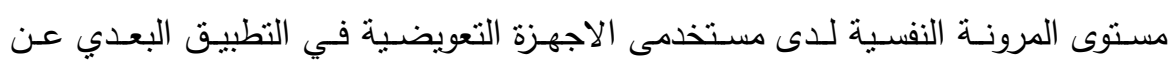
التطبيق القبلى. وبمقارنة قيمة إيتا ، ، مربع أوميجا w2 بالجدول المرجعى المقترح ( ) لتحديد مستويات

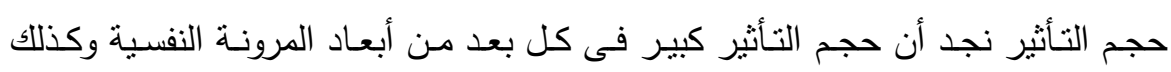

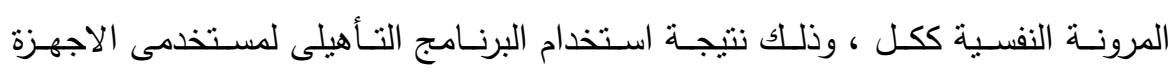
التعويضية.

وقد تبين مما سبق وجود تأثير للبرنامج التأهيلى على مستوى المرونة النفسية لدى

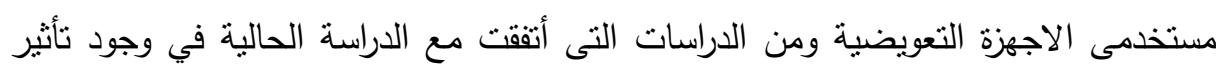
للبرامج التأهيلية والارشادية على مستوى المرونة النفسية:

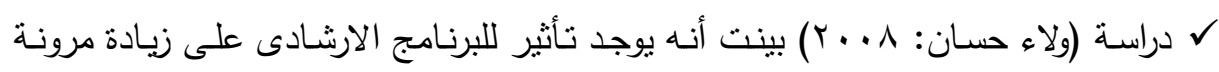
الانا لاى الطالبات. ل ودراسة (محمد عثمان : • ( • Y) اثارت إلى فعالية البرنامج الإرشادي المستخدم ودوره في تتمية المرونة النفسية الإيجابية لاى افراد المجموعة التجريبية من الثباب الجامعي.

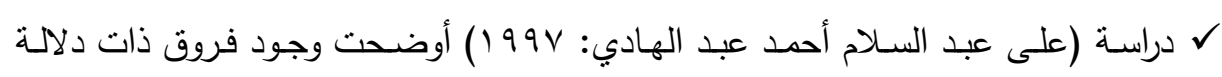
إحصائية بين مجموعة حالات البتر الذين لم ينلقوا برامج تأهيلية وبين مجموعة البتر الذين

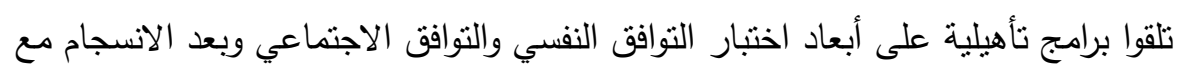
المجتمع لصالح مجموع حالات البتز الذين تلقوا برامج تأهيلية 
كما بينت بعض الدراسـات الاهتمـام بتأثير العوامل المختلفة على تكوين المرونـة النفسية ومنها: ل دراسة ناك - هو كيم (2005" , Tack-ho kim)حيث اوضحت وجود فروق فى المرونة النفسية بين الطلبة (مجموعة تميزت بالمرونة ومجموعة تميزت بسوء التكيف ) واعتمد ذلك

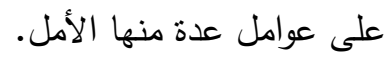
ل دراسـة لاكى (lacy,2005) بينــت أن المسـاندة الاجتماعيـة عامـل مســاهم فـى المرونــة النفسية. ل دراسـة (2009 20tzl) حيث أيدت أن مظاهر التفكير الابتكارى مؤشر هام للمرونـة الإيجابية.

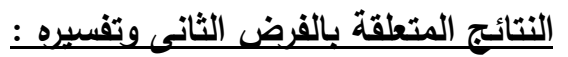

نص الفرض الثانى :" ثوجد فروق ذات دلالة إحصـائية بين منوسطات درجات المجموعـة التجريبية في التطبيق القبلى والتطبيق البعدي في صورة الذات ككل وفى أبعادها الفرعية كلاً على حد لصالح التطبيق البعدى. وللتحقق من هذا الفرض قام الباحث بإتباع الخطوات التالية:

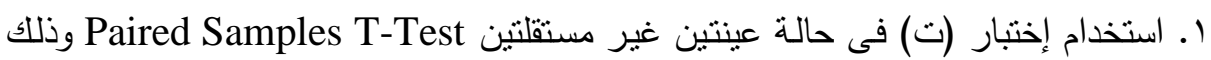
للتعرف على معنوية تأثير البرنامج التأهيلى على المرونة النفسية لدى مستخدمى الاجهزة التعويضية.

r. حساب المتوسط الحسابى والانحراف المعيارى لكلاً من التطبيق القبلى والتطبيق البعدي.

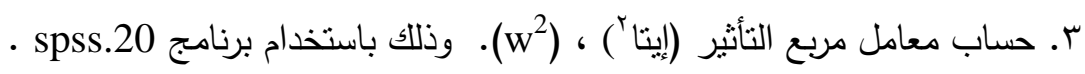


جدول (†): قيمة (ت) ودلالتها الاحصائية ، قيمة (إيتا؟)، مربع أوميجا، مقدار حجم تأثير

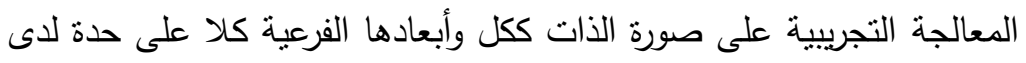

مستخدمي الاجهزة التعويضية في التطبيق البعدى

\begin{tabular}{|c|c|c|c|c|c|c|c|c|c|}
\hline \multirow{2}{*}{ التأثثر } & \multirow{2}{*}{ قريمة } & \multirow{2}{*}{ قيتيمة } & \multirow{2}{*}{ قيمة } & \multirow{2}{*}{ الدرجية } & \multicolumn{2}{|c|}{ ن = = البطبيق البعي } & \multicolumn{2}{|c|}{ ن ن = التطبيق القبلى } & \multirow{2}{*}{ البيان } \\
\hline & & & & & ع & re & ع & P & \\
\hline جبيرً & $\cdot, 9 \curlyvee \wedge$ & $\cdot, 900$ & $Y V, A V$ & TV & $1 \%, \leqslant 0$ & $1.9,95$ & $v, v_{0}$ & $r q, \pi$ & والثسمى صورة \\
\hline جبير & •, $\vee 99$ & • & 10, 10, & rV & $\varepsilon, \lambda T$ & $09,9 \vee$ & 9,11 & $r r, v$ & الانفاتل \\
\hline كبيرٍ & $\cdot, 91$. & $\cdot, 9 \leq Y$ & $T \varepsilon, O V V$ & $r v$ & $r_{\cdot,}, v_{0}$ & $\mid r V, T \Lambda$ & ד, ז & $\varepsilon r, \wedge q$ & الاجتعلاقاتة \\
\hline كبيرً & $\cdot, 9 \vee 0$ & $\cdot, 9 \wedge \varepsilon$ & $\varepsilon \vee, 991$ & rV & $r_{\cdot}, r_{0}$ & rqv, Oᄉ & Tr,YT & $\| V, r \varepsilon$ & مقياس \\
\hline
\end{tabular}

اتضح من الجدول (r) ما يلى:

وجود فروق ذات دلالة إحصائية عند مستوى دلالة ( إ., •) بين النطبيق القبلى والتطبيق البعدي للمجموعة التجريبية في صورة الذات ككل وجميع أبعادها المتمتلـة في (صورة الذات الجسمى والثخصى ، صورة الذات الانفعالى ، صورة الذات والعلاقات الاجتماعية)

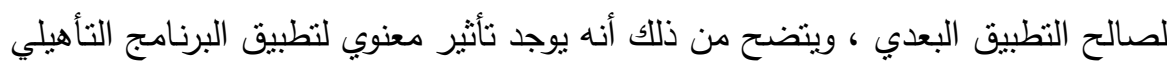
على صورة الذات لدى مستخدمي الاجهزة التعويضية.

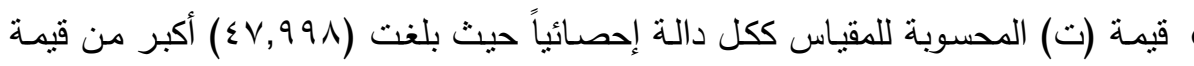

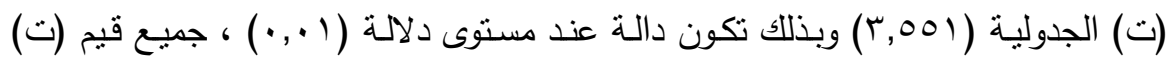
المحسوبة لكل بعد من ابعاد المقياس دالة عند مستوى دلالة (1 +, ·) مما يشير إلى ارتفاع مستوى صورة الذات لدى مستخدمى الاجهزة التعويضية في التطبيق البعدي عن التطبيق 
وبمقارنة قيمة إيتا' ، مربع أوميجا w² بالجدول المرجعى المقترح ( V ) لتحديد مستويات

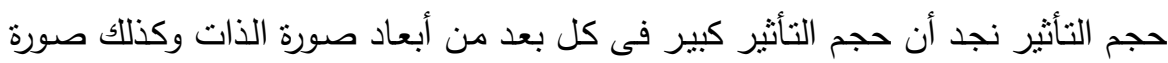

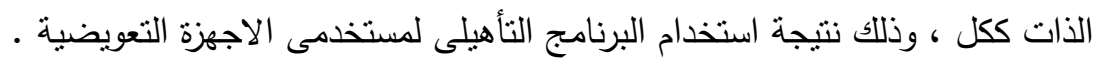

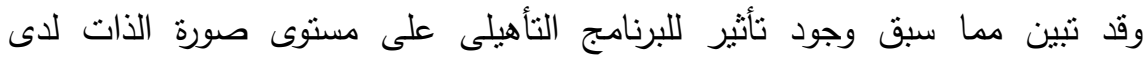
مستخدمى الاجهزة التعويضية ومن الدراسات التى أتفقت مع الدراسة الحالية في وجود تأثير لئير

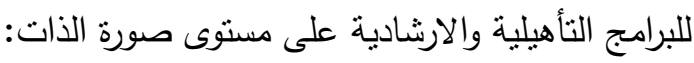

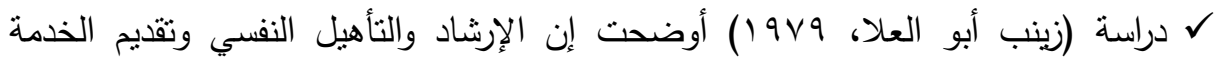

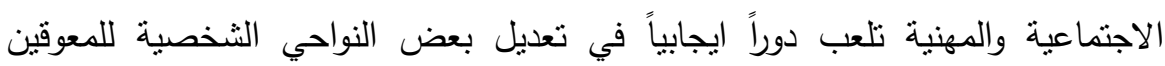

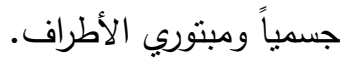

ل دراسة: (محمد عبد الرحيم، (991) أثنارت إلى وجود فروق ذات دلالة إحصائية بين

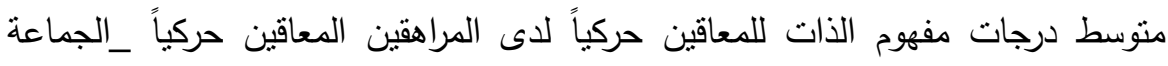

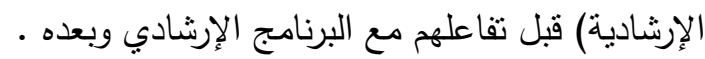

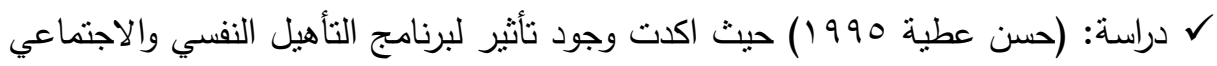
فى رفع وتتمية مستوى تقدير الذات لدى عينة من المعوقين مبتوري الأطراف.

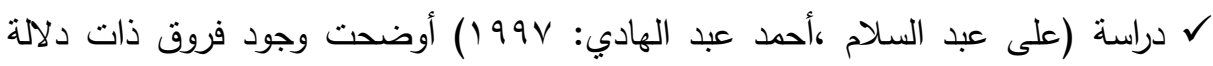
إحصائية بين حالات البتر الذين لم يتلقوا برامج تأهيلية، وحالات البتر الذين تلقوا برامج

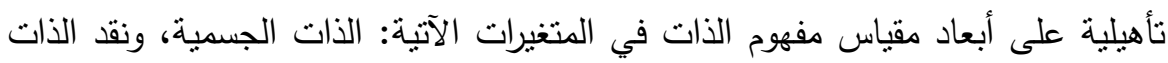
لصالح مجموعة حالات البتر الذين تلقوا برامج تأهيلية. نص الفرض الثالث:" توجد علاقة ارتباطية موجبة ذات دلالة إحصائية بين درجات

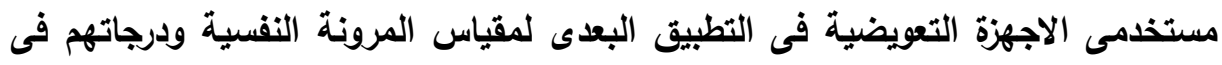

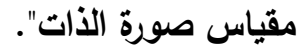
وللتحقى من هذا الفرض قام الباحث بإتباع الخطوات التالية : ا. استخدام معامل إرتباط بيرسون Person Correlation وذلك للتعرف على نوع ومستوى العلاقة بين المرونة النفسية صورة الذات لدى مستخدمى الاجهزة العويضية. 
كرم عزت وآخرون

جدول (V): العلاقة بين الدرجات البعدية لمستخدمى الاجهزة التعويضية في مقياس المرونة النفسية ودرجاتهم فى مقياس صورة الذات

\begin{tabular}{|c|c|c|c|c|}
\hline \multicolumn{4}{|c|}{ صورة الذات } & \multirow[b]{2}{*}{ المرونة النفسية } \\
\hline مقياسلى & صورة الألات الاتماتية & الأات & صورة الألشسى & \\
\hline$\cdot, r \circ 4$ & $*, \sum 1 \%$ & $\cdot, \Gamma \cdot 0-$ & $\cdot, 1 \leq r-$ & القرة على تكوين علاقات اجتماعية مع \\
\hline$\cdot, .79$ & $\cdot, 101$ & $\cdot, 1 \wedge \wedge-$ & $\cdot, \cdot 71-$ & القدرة على التحكم فى الانفعالات \\
\hline$\cdot, \cdot$, t & $\cdot, \cdot r r$ & $\cdot, .0 r$ & $\cdot, \ldots 1-$ & القدرة على اتخاذ القرارات والتخطيط لحل \\
\hline$\cdot, I \vee \wedge$ & $\cdot, r q \wedge$ & $\cdot, r \leqslant Y-$ & $\cdot, 1 \cdot 7-$ & إجمالى مقياس المرونة النفسية \\
\hline
\end{tabular}

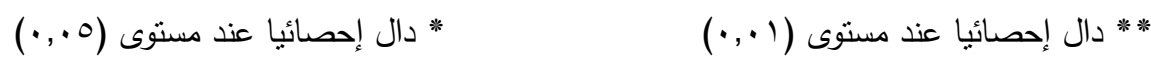

يلاحظ من الجدول السابق:

• توجد علاقة إرتباطية موجبه ذات دلالة إحصائية عند مستوى دلالة (ه.,. ) بين صورة الذات والعلاقات الاجتماعية والقدرة على تكوين علاقات اجتماعية مع الاخرين.

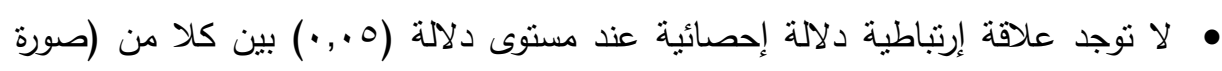

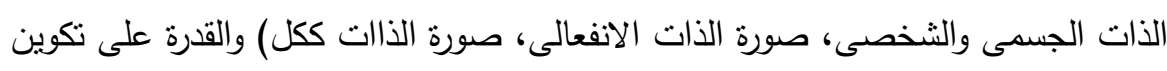
علاقات اجنماعية مع الاخرين. • لا نوجد علاقة إرتباطية دلالة إحصائية عند مستوى دلالة (0. . •) بين كلا من (صورة

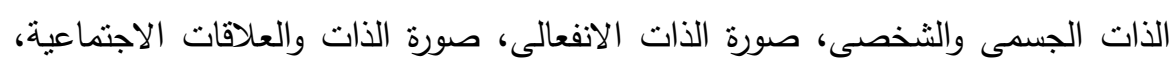
صورة الذات ككل) والقدرة على التحكم فى الانفعالات.

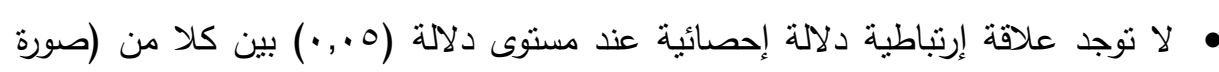

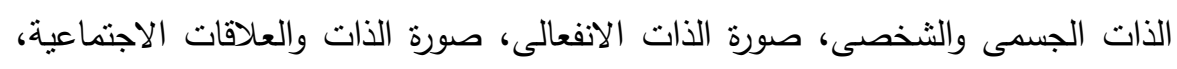
صورة الذات ككل) والقدرة على اتخاذ القرارات والتخطيط لحل المشكلات.

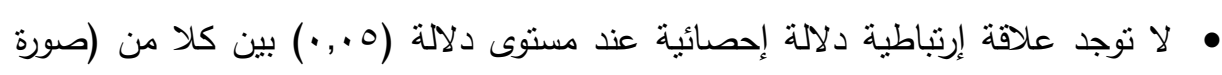

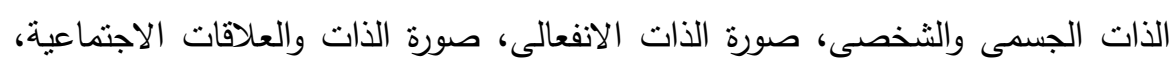
صورة الذات ككل) والمرونة النفسية ككل. 
وقد تبين مما سبق عدم وجود علاقة ذات دلالة إحصائية عند مستوى دلالة (0. . ) بين

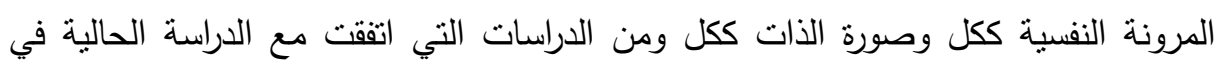
ذلك:

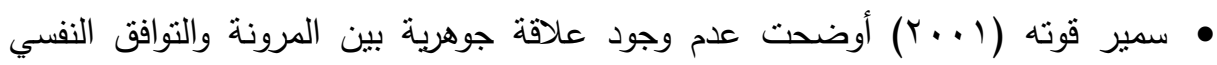
خلال الأحداث العنيفة في الاتتفاضة الفلسطينية الكبرى . • دراسة: أثرف عطية (1) (1) أوضحت وجودعلاقة إرتباطية سالبة دالة إحصائيا بين درجات الطلاب على مقياس المرونة النفسية الاكاديمى ودرجاتهم على مقياس تقدير

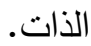

\section{التئو=ياتص}

1-الاهتمام بالمعاقين ومعاملتهم المعاملة الحسنة، ودمجه في المجتمع وإشراكهم في

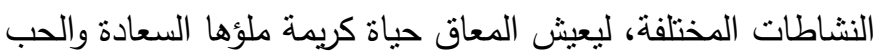

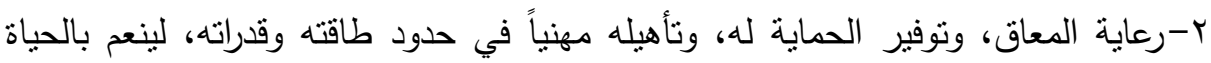
الكريمة بالإضافة إلى تطوير برامج تعليمية خاصة تنتاسب مع الوضع الصحي للمعاق.

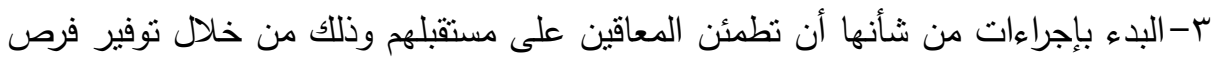
العمل المناسب لهم؛ وإثراكهم في بناء المجتمع لأن النظرة إلى المعاق على أنى أنه إنسان مريض وغير قادر ، وليس لديه ما يساهم به في المجتمع تزيد من عزلته وانطوائه ومن قلقه لتهاه على مستقبله ع-تطوير برامج التدريب المهني للمعوقين حركياً تتلاءم مع منطلبات سوق العمل، مع تصع تضمين برامج التوظيف المدعوم توفير وظائف للمعوقين تتناسب ودرجة إعاقتهم. 


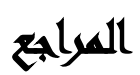

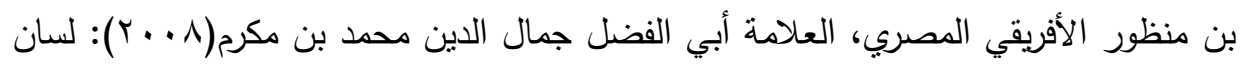
العرب "مادة ذات"ج با، دار المعارف، الفيل القاهرة.

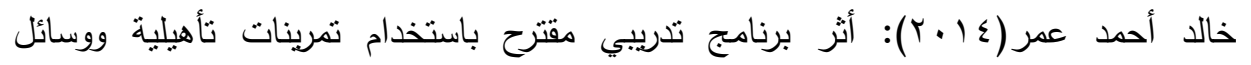

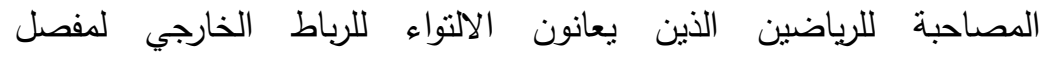

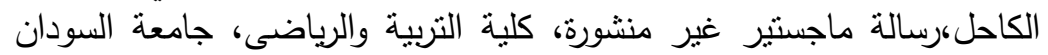
اللعلوم والتكنولوجيا.

زكريا أحمد الشربيني ( ع . . ؟):طفل خاص بين الإعاقات والمتنزمات- تعريف وتتخيص، دار الفكر العربي، القاهرة. (بان.

عدلي السمري(ب ( • ب): دراسة المشكلات الاجتماعية، الناشر الزعيم للنشر القاهرة.

عدنان إبراهيم - تاج السر عبد الله،( (991 ()): المعوقون، بدون دار نشر ، سبها.

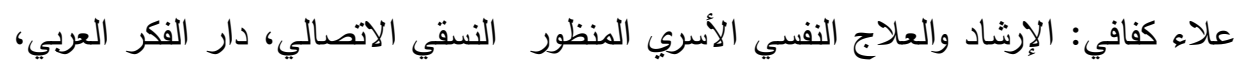

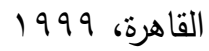

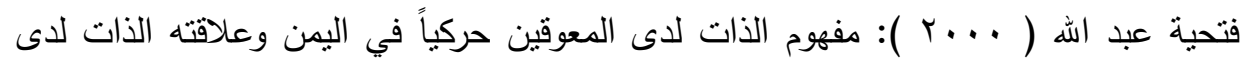

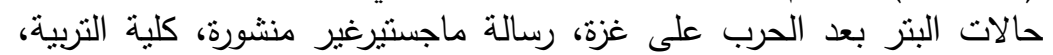

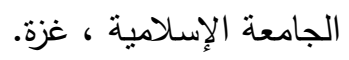

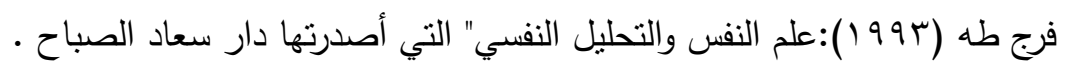

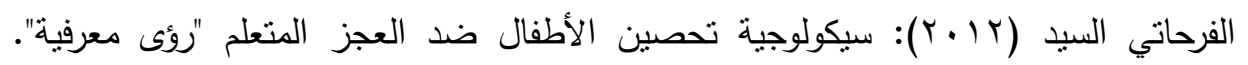

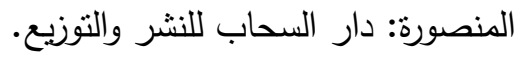

محمد عبد السلام البواليز ( ... ب): الإعاقة الحركية والثشلل الدماغي كدار الفكرللطباعة والنشر

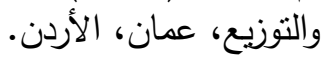

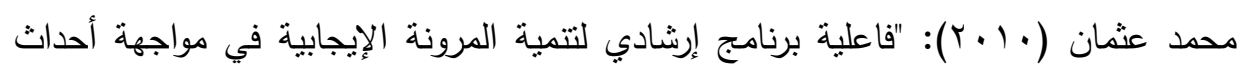

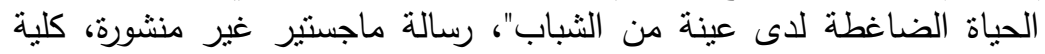

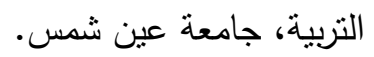

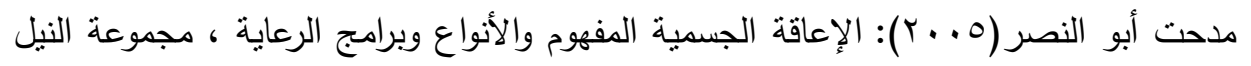

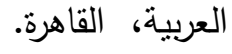

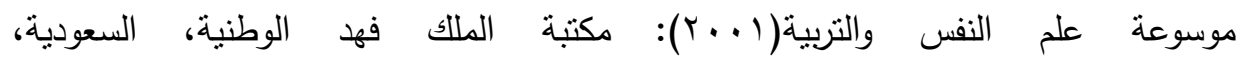
=https://www.google.com.eg/search?newwindow

202 المجلد الخامس والأربعون، الجزء الثالث، مارس 9 . ب. 


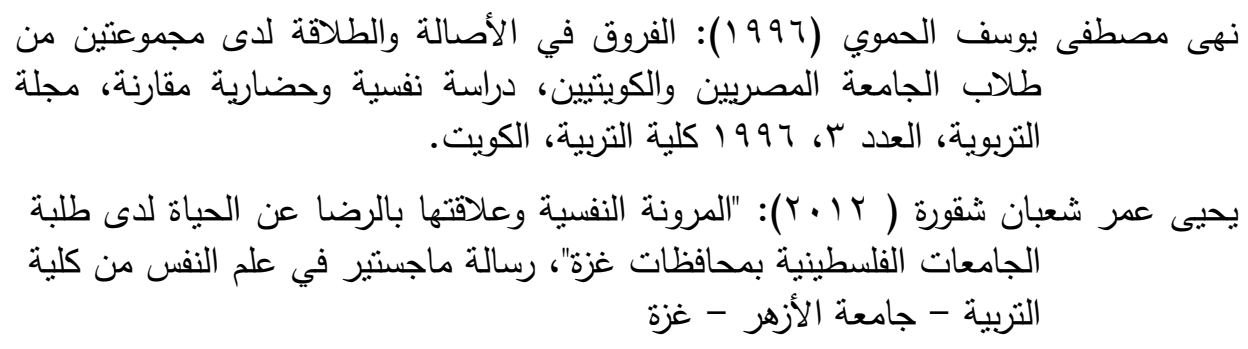

APA American Psychological Association, (2002). The road to resilience, 750, First Street, NE, Washington DC.

Burger. H \& Maricek CRT. 2007. Disability and Rehabilitation: Return to work after lower limb amputation. Ephraim, Dillingham, Sector, Pezzin.

Brown, J. D., Collins, R. L., \& Schmidt, G. W. (1988). Self-esteem and direct versus indirect forms of self-enhancement. Journal of Personality and Social Psychology

Burger. H \& Maricek CRT. 2007. Disability and Rehabilitation: Return to work after lower limb amputation.

Ephraim, Dillingham, Sector, Pezzin, \&MacKenzie, 2003; Unwin, 2000

Sarah, R . Covangh, Lisa, M.Shin, Nasser Karmataz and Scott L.Raved (2007) 


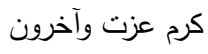

\title{
THE EFFECTIVENESS OF A REHABILITATION \\ PROGRAM TO ACQUISTIION PSYCHOLOGICAL \\ FLEXIBILITY AND ITS IMPACT ON SELF-IIMAGE \\ OF USERS OF PROSTHETIC DEVICESARTIFICIAL \\ ORGANISMS APPLAANCES \\ A COMPARATIVE STUDYAMONG MALES \\ AND FEMALES IN RURAL AND URBAN AREA
}

[8]

\begin{abstract}
Karam Ezzat $^{(1)}$; Mahmoud E. Abou El Nil ${ }^{(1)}$; Zainb B. Abd El Hamid ${ }^{(2)}$ and Farhati E. Mahmoud ${ }^{(3)}$

1) Medical Devices Department 2) Faculty of Arts, Ain Shams University 3) Faculty of Medicine, Ain Shams University 4) The National Center for Central Evaluation 4
\end{abstract}

\begin{abstract}
The study aimed at verifying the effectiveness of a rehabilitation program to acquire psychological flexibility and its impact on the selfimage of compensatory users. A comparative study between males and females from rural and urban areas. The sample of the study consisted of (30) exploratory samples, (38) tribal and a number of compensatory users. The researchers used the descriptive approach, the semiexperimental method and the tools. D researchers, a measure of selfresearchers set up an image. The preparation program for the users of compensatory devices prepared by researchers. The study reached a number of important results: 1 .

1- There are statistically significant differences at the level of $(0.01)$ between the tribal application and the post-application of the experimental group in the psychological flexibility as a whole and all its dimensions (ability to form social relations with others, ability to
\end{abstract}

$$
\text { المجلد الخامس والأربعون، الجزء الثالث، مارس } 9 \text { ب ـ }
$$


control emotions, ability to make decisions and planning to solve problems) for the application of dimension and life.

2- There is no correlation relationship statistical significance at the level of significance (0.05) between the (self-image and physical image, self-image of emotional, self-image and social relations, the image of the whole and the ability to make decisions and planning to solve problems. 